\title{
Comparative proteomic and transcriptomic analyses provide new insight into the formation of seed size in castor bean
}

\author{
Anmin $\mathrm{Yu}^{1,2}$, Fei Li ${ }^{2}$ and Aizhong Liu' ${ }^{1 *}$
}

\begin{abstract}
Background: Little is known about the molecular basis of seed size formation in endospermic seed of dicotyledons. The seed of castor bean (Ricinus communis $\mathrm{L}$.) is considered as a model system in seed biology studies because of its persistent endosperms throughout seed development.

Results: We compared the size of endosperm and endospermic cells between ZB107 and ZB306 and found that the larger seed size of ZB107 resulted from a higher cell count in the endosperm, which occupy a significant amount of the total seed volume. In addition, fresh weight, dry weight, and protein content of seeds were remarkably higher in ZB107 than in ZB306. Comparative proteomic and transcriptomic analyses were performed between large-seed ZB107 and small-seed ZB306, using isobaric tags for relative and absolute quantification (iTRAQ) and RNA-seq technologies, respectively. A total of 1416 protein species were identified, of which 173 were determined as differentially abundant protein species (DAPs). Additionally, there were 9545 differentially expressed genes (DEGs) between ZB306 and ZB107. Functional analyses revealed that these DAPs and DEGs were mainly involved in cell division and the metabolism of carbohydrates and proteins.
\end{abstract}

Conclusions: These findings suggest that both cell number and storage-component accumulation are critical for the formation of seed size, providing new insight into the potential mechanisms behind seed size formation in endospermic seeds.

\section{Background}

Seeds are vitally important for the economic and nutritional value of most agricultural products. Consequently, improving the traits associated with seed phenotypes has increasingly received attention for its implications in modern agricultural research. Seed size is a major determinant of crop yield and is one of major traits concerned with the breeding of oil crops that is strongly selected for crop domestication [1]. Seed size is largely governed by genetic factors during the seed-filling process, though the formation process of seed size is also strongly affected by biotic and abiotic stresses [2]. Seed-filling is the period when embryogenesis and endosperm genesis occur, a period that encompasses complex cellular processes and the rapid accumulation of seed storage

\footnotetext{
* Correspondence: liuaizhong@mail.kib.ac.cn

${ }^{1}$ Key Laboratory for Forest Resources Conservation and Utilization in the Southwest Mountains of China, Ministry of Education, Southwest Forestry University, Kunming 650224, People's Republic of China

Full list of author information is available at the end of the article
}

reserves. Although several QTLs or genes (in particular, transcription factors) have been identified and/or cloned from numerous species such as Arabidopsis [3], rice [4], and maize [5], the role of a single gene appears to be minor, and little is understood about the regulatory networks that provide global control over the process of seed size formation. Physiologically, the biosynthetic pathways responsible for the accumulation of seed storage reserves are now largely defined [6], but much less remains unknown about the mechanisms that determine different seed sizes during seed-filling.

The seed of castor bean (Ricinus communis L., Euphorbiaceae, $2 n=20$ ) is an desirable model system for studying seed biology because of the large and persistent endosperm. It is therefore ideal to study the mechanisms behind seed size formation, as the endosperm contains $60 \%$ fatty acids and $34 \%$ protein [6, 7]. Among all the vegetable oils, castor oil is a highly valued resource in the industry, due to its high ricinoleic acid (over 85\%) content, an unusual fatty acid that consists of 18 
carbons, a double bond between C9 and C10, and a hydroxyl group attached to C12. Owing to its excellent solubility in either ethanol or methanol, castor oil has been proposed as a source of high-value biodiesel [8-10]. Because of its high economic value and strong capacity for environmental adaptation, castor bean is widely cultivated in tropical, sub-tropical, and warm-temperate countries, particularly in India, China, and Brazil [11]. With the increasing demand for castor oil in many countries, breeding and the genetic improvement of castor bean varieties for both seed and oil yields are attracting much attention from breeders [12]. Seed size is a critical trait associated with crop yield in castor bean and elucidating the molecular mechanisms that underlie the formation of seed size would greatly facilitate the improvement of genetic engineering in castor bean varieties.

Currently, proteomic and transcriptomic sequencing have offered useful approaches to investigate the integrated mechanisms that underlie both the regulatory networks of seed size formation as well as the accumulation of carbohydrates, proteins, and fatty acids [13]. Recently, iTRAQ technology has also offered a useful quantitative proteomic method to study the seed development in many plant species such as wheat, soybean, rapeseed, and Medicago truncatula [14-17]. Differential proteomic analysis on developing castor bean seeds has been conducted with two goals. The first is to identify proteins involved in the biosynthesis of fatty acids in the endosperm of castor bean [6]. The second is to investigate the spatial and temporal trends of protein abundances associated with protein synthesis and degradation in the maternal seed tissues of nucellus [18]. So far, the analysis of embryogenesis, endosperm genesis, and the primary metabolisms during the seed development of castor bean has deserved little attention. In this study, we performed comparative proteomic and transcriptomic analyses on developing seeds from the two inbred varieties ZB107 and ZB306 that have different seed sizes using iTRAQ and RNA-seq techniques. The aim of this study was to identify the candidate genes involved in the formation of seed size at both the levels of transcription (mRNA) and translation (protein), as well as provide novel insights to understand the potential molecular basis that regulates the formation of seed size in castor bean.

\section{Results}

\section{Morphological and weight changes in seeds during development}

The length of time of seed development, beginning with pollination to maturation, may exert significant influence on castor varieties, in accordance with the morphological changes of endosperm and our previous study of seed coat development $[19,20]$. The seed development process could be separated into three stages: early, middle, and late. Seeds progressed through these three stages in 1-25, 26-45, and 46-75 days after fertilization (DAF) in ZB107, as well as in 1-15, 16-30, and 31-60 DAF in ZB306, respectively (Fig. 1a). The early stage was characterized by active cell division and was associated with increased cell number in the young seeds. In the middle stage, cell enlargement caused the seed weight and volume to increase rapidly (Fig. 1a). During the late stage, fresh weight (FW) of single seed peaked and then gradually decreased. From early to late stages, FW of single seed increased 8.5-fold in ZB107 (from 142.87 \pm $2.27 \mathrm{mg}$ to $1207.03 \pm 0.2 \mathrm{mg}$ ), whereas FW increased 6.93-fold in ZB306 (from $70.53 \pm 0.87 \mathrm{mg}$ to $484.87 \pm$ $0.71 \mathrm{mg}$ ) (Fig. $1 \mathrm{~b}$ and c). Correspondingly, dry weight (DW) of single seed increased 38.5-fold from the early to late stages in ZB107 (from $24.9 \pm 0.56 \mathrm{mg}$ to $924.87 \pm$ $0.47 \mathrm{mg}$ ), and a 35.45 -fold increase (from $10.97 \pm 0.35$ $\mathrm{mg}$ to $390.23 \pm 0.97 \mathrm{mg}$ ) was observed in ZB306 (Fig. 1b and $c)$. The protein content of dry single seed exhibited a similar trend during seed development, increasing from $6.2 \pm 0.36 \mathrm{mg}$ to $285.1 \pm 0.4 \mathrm{mg}$ in $\mathrm{ZB} 107$, and from $3.1 \pm 0.26 \mathrm{mg}$ to $97.5 \pm 0.75 \mathrm{mg}$ in ZB306. Similarly, seed size also increased rapidly from the early to late stages in castor bean (Fig. 1a). Seed length increased from 18.85 $\mathrm{mm}$ to $37.7 \mathrm{~mm}$ in ZB107, and it increased from 16.9 $\mathrm{mm}$ to $26 \mathrm{~mm}$ in ZB306. Seed width increased from 13 $\mathrm{mm}$ to $26 \mathrm{~mm}$ in ZB107, and it increased from $11.7 \mathrm{~mm}$ to $16.5 \mathrm{~mm}$ in ZB306.

As a typical dicot endospermic seed, the endosperm occupies roughly $90 \%$ of the volume of the castor bean seed, so the differences in seed size and weight of ZB107 and ZB306 depend mainly on endosperm size. The endosperm area of ZB107 was nearly 2.51 -fold larger than ZB306 (Fig. 2a and b). To further investigate whether endosperm size variation was determined by cell size or cell number, we performed a microscopic analysis of the endosperm tissues of ZB107 and ZB306. The variation of cell size and cell number were statistically insignificant between ZB107 and ZB306; however, cell density varied among the internal, middle, and external parts of the two varieties (Fig. 2a, c, d and e). These results indicate that the difference in endosperm size between large-seed ZB107 and small-seed ZB306 is determined by cell number rather than cell size, which is consistent with our previous observations of seed coat in castor bean, in which we noted that large seed coat area resulted from more cell numbers [19].

\section{Comparative proteomic analysis of large-seed ZB107 and small-seed ZB306}

To investigate the protein species involved in seed size formation in castor bean, we performed iTRAQ analysis on large-seed ZB107 and small-seed ZB306. The seed 


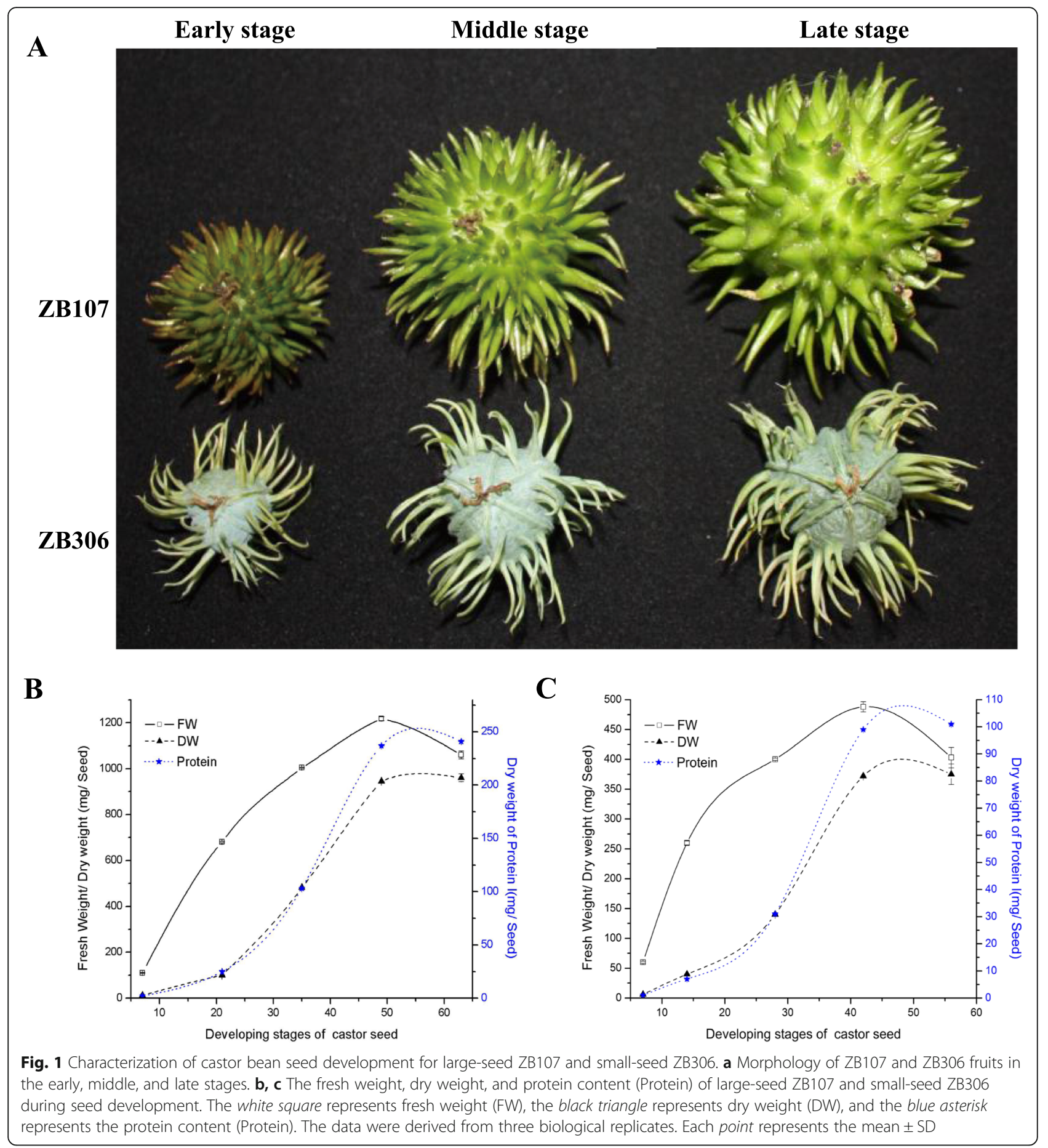

samples of ZB107 from the early, middle, and late stages were used to extract protein, and equal amounts of protein samples from different development stages were mixed as the large-seed sample, and the corresponding seeds of ZB306 in the above development stages were mixed as the small-seed sample. A total of 156,386 spectra were generated, of which 12,674 were matched to the Peptide Spectrum Match (PSM), and 10,506 were unique after eliminating low-score spectra (Additional file 1: Table S1). By searching against the reference genome database with the Mascot 2.2 program, these unique spectra that met the strict confidence criteria were matched with 3963 known peptides, of which 3681 peptides were unique (Additional file 1: Table S1). Finally, 1416 protein species containing at least one unique peptide were identified from the developing seeds of ZB107 

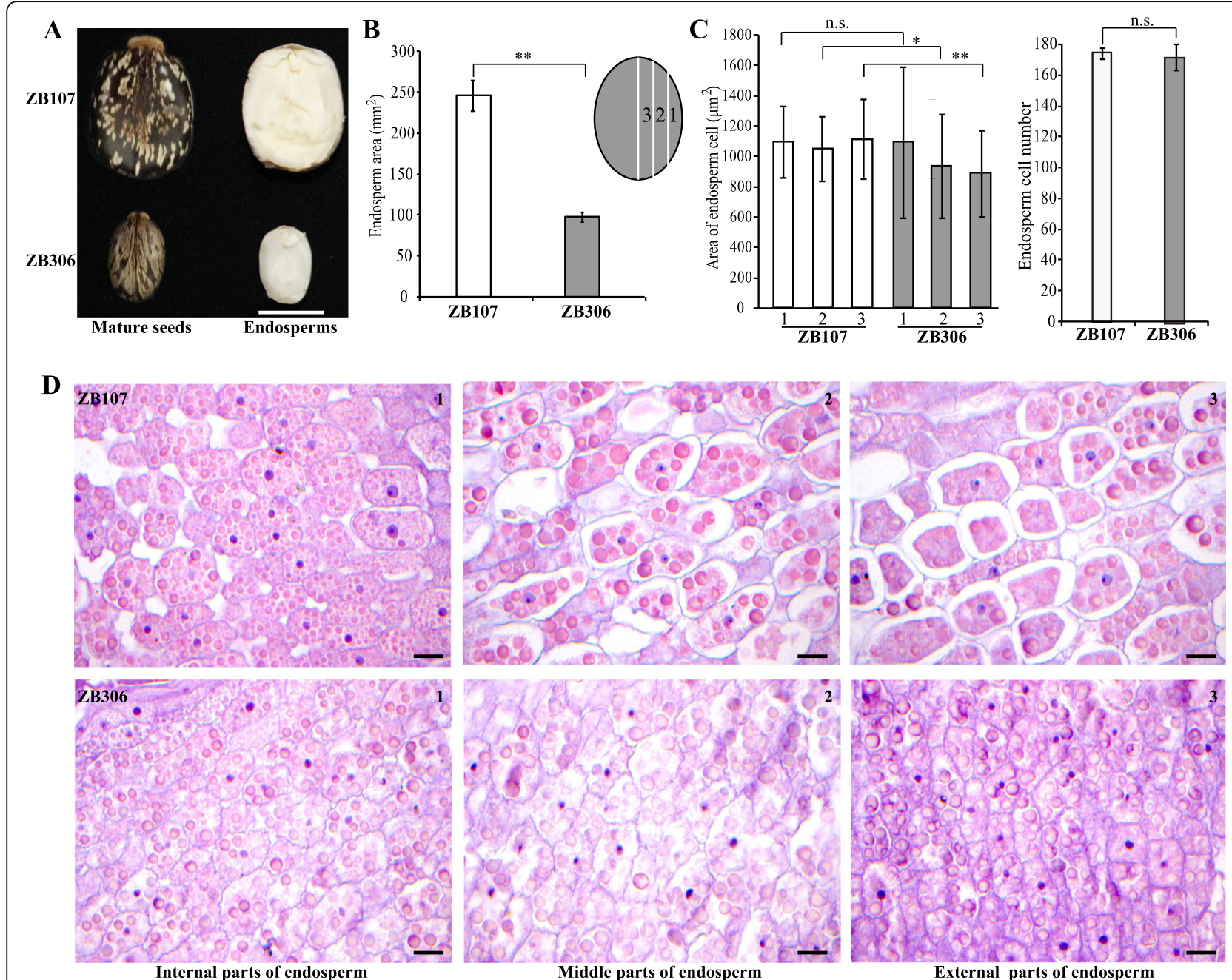

Fig. 2 The morphological and cytological characteristics of large-seed ZB107 and small-seed ZB306. a The exact appearances of mature seeds and endosperms of ZB107 and ZB306. Scale bar = $1 \mathrm{~cm}$. b Comparison of the surface area of endosperm between ZB107 and ZB306. c, d Histological analysis of the endosperm cell area and cell number of ZB107 and ZB306. e Cross-sections of the endosperm was divided into internal (1), middle (2), and external (3) parts. Data are reported as mean \pm SD from 10 seeds. The significance was analyzed using Student $t$-test (The asterisk indicates significance, ${ }^{*} p<0.05$, ${ }^{* *} p<0.01$, n.S., no significant difference). Scale bar $=25 \mu \mathrm{m}$

and ZB306 (Additional file 2: Table S2). Of the 1416 protein species, 1028 were divided into 23 COG clusters according to their functional annotation (Additional file 3: Figure S1). Among these, "posttranslational modification/protein turnover/chaperones" was the functional category with the highest representation $(17.41 \%, 179 / 1028)$, followed by "general function prediction only" (14.40\%, 148/1028), "translation/ ribosomal structure/biogenesis" (11.67\%, 120/1028), and "energy production and conversion" (10.41\%, 107/1028). Furthermore, eight protein species were classified into "cell cycle control, cell division, or chromosome partitioning", and six of them were identified as calmodulin or calcium-dependent protein kinase (Additional file 4: Table S3). In addition, 1157 identified protein species were categorized into three groups based on GO category enrichment analysis: biological process, cellular component, and molecular function. Results indicated that in the biological process category, metabolic process $(60.41 \%, 699 / 1157)$ was the most represented, followed by cellular process $(55.92 \%, 647 / 1157)$ and response to stimulus $(35.70 \%, 413 / 1157)$ (Additional file 5: Figure S2). The largest category is related to cell and cell part $(82.80 \%$, 958/1157) in cellular component. Specifically, three protein species related to cell division were identified, including auxin-repressed $12.5 \mathrm{kDa}$ protein (ARP, 30190.t000561), serine carboxypeptidase (SC, 29489.t000001, 29,745.t000011), and eukaryotic translation initiation factor 5a (eIF-5A, 29, 687.t000001) (Table 1).

Using a fold change $\geq 1.5$ or $\leq 0.67$ and a $p$-value less than 0.05 , a total of 173 protein species were identified as differentially abundant protein species (DAPs) between ZB107 and ZB306. Of these DAPs, 57 increasedabundance and 116 decreased-abundance protein species 
Table 1 Identification of DAPs between ZB107 and ZB306

\begin{tabular}{|c|c|c|c|}
\hline Metabolic pathway & Protein ID & Description & FC \\
\hline \multirow[t]{4}{*}{ TCA cycle } & $29,600 . t 000017$ & aconitase, putative & -0.6 \\
\hline & $29,794 . t 000105$ & malic enzyme & -0.62 \\
\hline & $30,226 . t 000050$ & citrate synthase (CS) & -0.48 \\
\hline & $29,628 . t 000002$ & isocitrate dehydrogenase (IDH) & 0.72 \\
\hline \multirow[t]{11}{*}{ Glycolysis } & $27,383 . t 000001$ & triosephosphate isomerase (TPI) & -0.64 \\
\hline & $29,601 . t 000014$ & pyruvate decarboxylase & -0.41 \\
\hline & $29,660 . t 000032$ & fructose-bisphosphate aldolase (FBA) & -0.64 \\
\hline & $29,692 . t 000012$ & phosphoglucomutase (PGM) & -0.65 \\
\hline & $30,169 . t 000047$ & glyceraldehyde 3-phosphate dehydrogenase (GAPDH) & -0.6 \\
\hline & $30,169 \cdot+000073$ & phosphoglycerate kinase (PGK) & -0.6 \\
\hline & $30,131 . t 000450$ & pyruvate kinase (PK) & -0.56 \\
\hline & $30,147 . t 000451$ & enolase & -0.65 \\
\hline & $29,736 . t 000093$ & pyruvate dehydrogenase (PDC) & -0.6 \\
\hline & $30,170 \cdot t 000437$ & glucose-6-phosphate isomerase (GPI) & -0.59 \\
\hline & 29,739.t000129 & sucrose synthase (SUS) & -0.69 \\
\hline \multirow[t]{4}{*}{ Fructose and mannose metabolism } & $27,766.0000004$ & Xylose isomerase & -0.67 \\
\hline & $29,842 \cdot t 000024$ & phosphofructo kinase (PFK) & -0.63 \\
\hline & $30,171 . t 000020$ & utp-glucose-1-phosphate uridylyltransferase & -0.83 \\
\hline & $27,914.0000023$ & NADP-specific isocitrate dehydrogenase (IDH) & -0.62 \\
\hline \multirow[t]{5}{*}{ Biosynthesis of amino acids } & $30,078 . t 000071$ & s-adenosylmethionine synthetase & -0.20 \\
\hline & $30,147 . t 000451$ & enolase & -0.65 \\
\hline & $29,739 . t 000101$ & 265 protease regulatory subunit & -0.58 \\
\hline & $29,172 . t 000012$ & xylem serine proteinase 1 precursor & -0.52 \\
\hline & $29,986 . t 000074$ & xylem serine proteinase 1 precursor & -0.57 \\
\hline \multirow[t]{4}{*}{ Cell division } & 29,489.t000001 & serine carboxypeptidase, putative & 4.09 \\
\hline & $29,745 . t 000011$ & serine carboxypeptidase, putative & -0.50 \\
\hline & $29,687 . t 000001$ & eukaryotic translation initiation factor $5 a$ & -0.54 \\
\hline & 30,190.t000561 & Auxin-repressed $12.5 \mathrm{kDa}$ protein & 2.24 \\
\hline \multirow[t]{17}{*}{ Ribosome } & $28,180 . t 000008$ & $60 S$ ribosomal protein L23a (SRPL23a) & -0.29 \\
\hline & $29,070 . t 000002$ & 60 S ribosomal protein L32 (SRPL32) & -0.48 \\
\hline & $29,703 . t 000077$ & 60 ribosomal protein L6 (SRPL6) & -0.41 \\
\hline & $29,743 . t 000009$ & 60 ribosomal protein L8 (SRPL8) & -0.54 \\
\hline & $30,071 \cdot t 000004$ & 605 ribosomal protein L13 (SRPL13) & -0.61 \\
\hline & $30,128 . t 000077$ & $40 \mathrm{~S}$ ribosomal protein $\mathrm{S3a}$ & -0.58 \\
\hline & $30,147 . t 000153$ & $60 S$ ribosomal protein L27a (SRPL27a) & -0.45 \\
\hline & $30,147 . t 000458$ & 40 ribosomal protein S13 (RPS13) & -0.56 \\
\hline & $30,147 . t 000462$ & 40S ribosomal protein S20 (RPS20) & -0.62 \\
\hline & $30,152 . t 000032$ & $60 S$ ribosomal protein L6 (SRPL6) & -0.55 \\
\hline & $28,076 . t 000001$ & 605 ribosomal protein L12 (SRPL12) & 1.75 \\
\hline & 29,588.t000012 & $40 \mathrm{~S}$ ribosomal protein S12 & 2.73 \\
\hline & $29,630 . t 000028$ & $40 \mathrm{~S}$ ribosomal protein S19 & 2.39 \\
\hline & 29,788.t000001 & 60 S ribosomal protein L35 (SRPL35) & 2.04 \\
\hline & $29,805.0000016$ & $40 \mathrm{~S}$ ribosomal protein $\mathrm{S} 23$ & 7.52 \\
\hline & $29,866 . t 000003$ & 605 acidic ribosomal protein P1 & 7.93 \\
\hline & $30,167 \cdot t 000025$ & $40 \mathrm{~S}$ ribosomal protein $\mathrm{S} 19$ & 2.48 \\
\hline
\end{tabular}


were detected in small-seed ZB306 compared to largeseed ZB107 (Fig. 3a and Additional file 6: Table S4). Furthermore, KEGG pathway enrichment analysis revealed that a total of 105 DAPs were featured high enrichment in "carbohydrate metabolism" (29.52\%, 31/105), "energy metabolism" (14.29\%, 15/105), "amino acid metabolism" $(9.52 \%, 10 / 105)$ and translation $(24.76 \%, 26 / 105)$, respectively (Fig. $3 \mathrm{~b})$. These results indicated that protein and carbohydrate metabolism were essential for the determination of seed size/weight of the two castor varieties. In the present study, a total of 19 DAPs involved in carbohydrate metabolism were identified, such as the tricarboxylic acid (TCA) cycle, glycolysis, as well as fructose and mannose metabolism (Table 1). Carbohydrate metabolism is a principal process for the rapid expansion of seed volume, especially in the early developmental stage, and the abundance of nearly all the DAPs involved in this process featured decreased levels in ZB306 (Table 1 and Fig. 3). In the TCA cycle, the abundance of aconitase $(29,600 . t 000017)$, malic enzyme (29, 794.t000105), and citrate synthase (CS, 30226.t000050) featured decreased levels in ZB306 compared to ZB107 (Additional file 7: Figure S3). Likewise, protein abundances of the enzymes involved in glycolysis were also decreased in ZB306 when compared to ZB107, such as triosephosphate isomerase (TPI, 27383.t000001), fructose-bisphosphate aldolase (FBA, 29660.t000032), phosphoglucomutase (PGM, 29692.t000012), and glyceraldehyde 3-phosphate dehydrogenase (GAPDH, 30169.t000047) (Table 1 and Additional file 7: Figure S3). Moreover, seven large ribosomal subunit proteins (28,180.t000008, 29,070.t000002, 29,703.t000077, 29, 743.t000009, 30,071.t000004, 30,147.t000153, and 30, 152.t000032) that are associated with the ribosomal process exhibited decreases in ZB306, while only three of $40 \mathrm{~S}$ ribosomal proteins $(30,128 . t 000077,30$, 147.t000458, and 30,147.t000462) were decreasedabundance protein species in ZB306 (Table 1 and Fig. 4c). Ribosome biogenesis play a fundamental role in cell growth by activating protein synthesis [21]. In
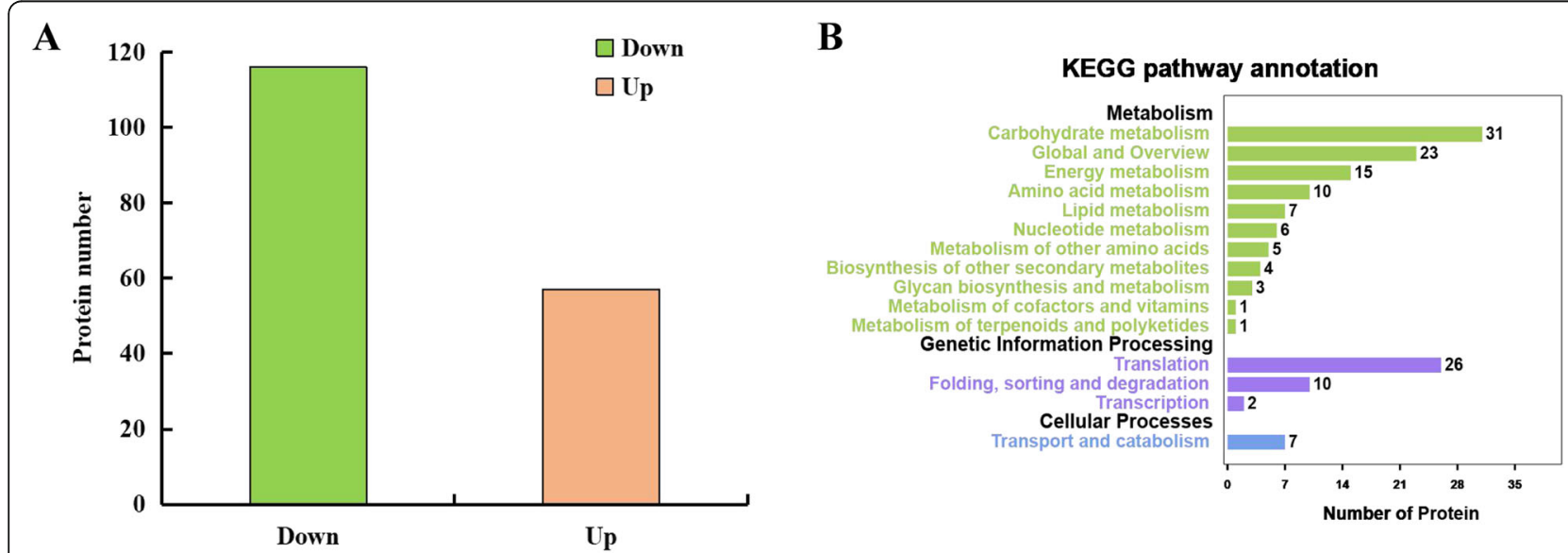

C
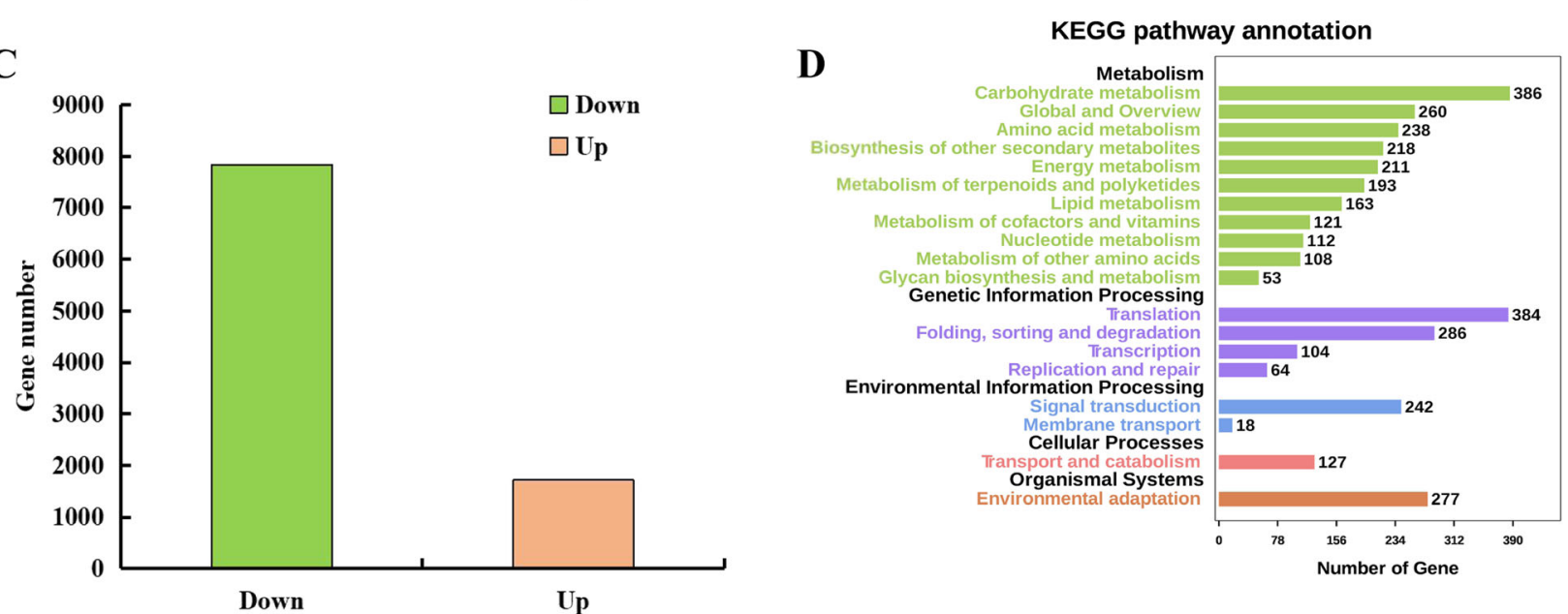

Fig. 3 Comparative proteomic and transcriptomic analyses of DAPs and DEGs between large-seed ZB107 and small-seed ZB306. a, c The number of increased-abundance (Up) and decreased-abundance (Down) protein species and genes in ZB306 compared to ZB107. b, d KEGG pathway annotation of DAPs and DEGs 


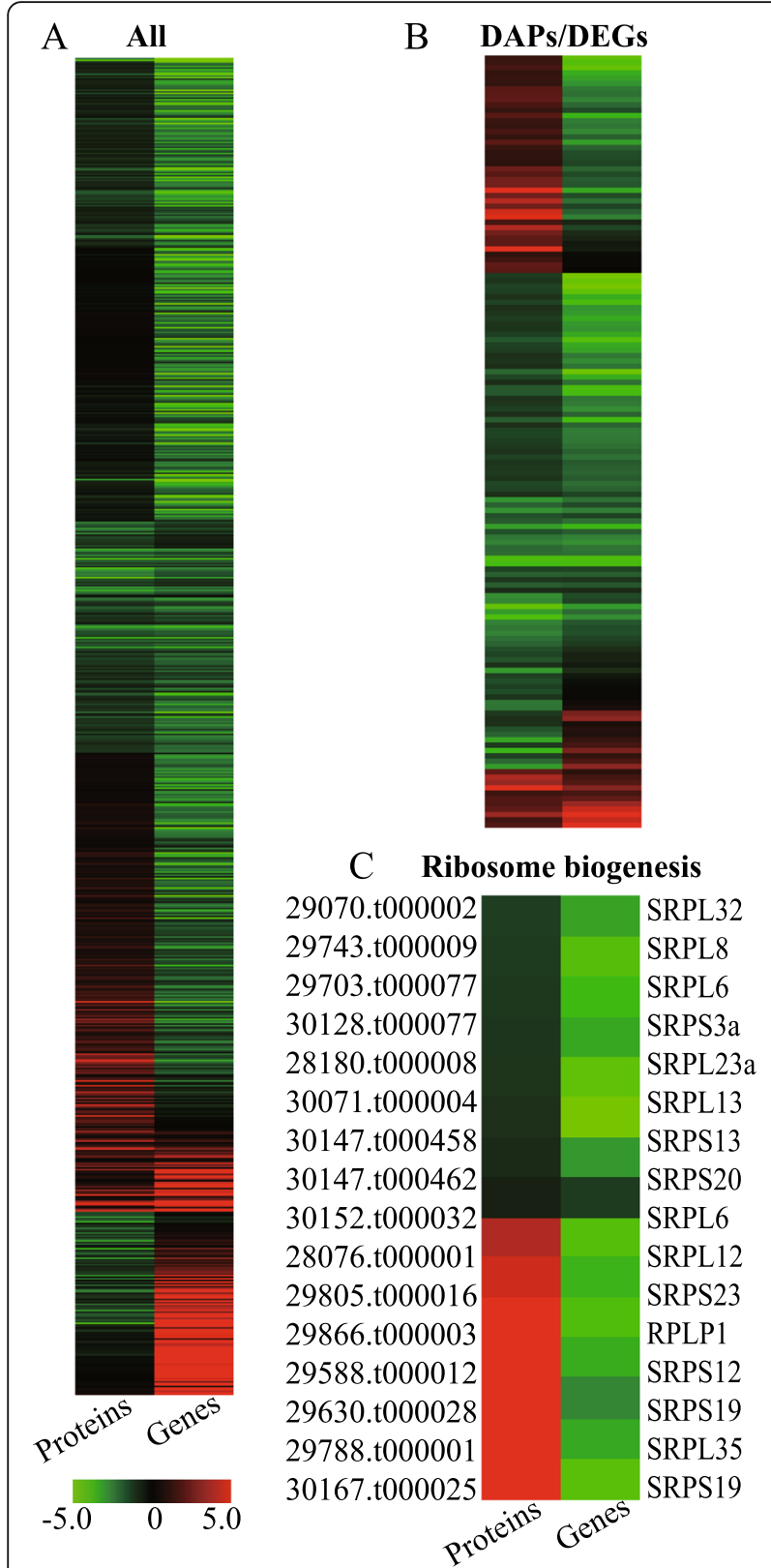

\section{Protein metabolic process}

28066.t000001 peptidylprolyl isomerase

29687.t000001

29739.t000101

29765.t000007

29815.t000017

29816.t000025

29986.t000074

30113.t000025

60638.00003

29646.t000007

29866.t000003

29489.t000001

30076.t000140

30128.t000431

30078.t000071

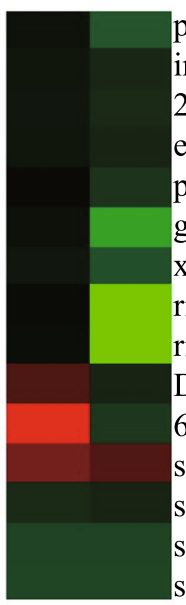

initiation factor $5 \mathrm{a}$

$26 \mathrm{~S}$ protease regulatory subunit

elongation factor 1 gamma

protein kinase APK1A

groes chaperonin

xylem serine proteinase 1 precursor

ricin-agglutinin family protein

ricin-agglutinin family protein

DDOST

60S acidic ribosomal protein $\mathrm{P} 1$

serine carboxypeptidase

s-adenosylmethionine synthetase

s-adenosylmethionine synthetase s-adenosylmethionine synthetase

\section{E Carbohydrate metabolism}

\begin{tabular}{|c|c|}
\hline 29794.t000105 & malic enzyme \\
\hline 27383.t000001 & TPI \\
\hline 27766.t000004 & xylose isomerase \\
\hline 30169.t000047 & GAPDH \\
\hline 29628.t000002 & IDH \\
\hline 30147.t000451 & enolase \\
\hline 29739.t000129 & SUS \\
\hline 30169.t000073 & PGK \\
\hline $29660 . t 000032$ & FBA \\
\hline 29736.t000093 & PDC \\
\hline 30170.t000437 & GPI \\
\hline 29601.t000014 & pyruvate decarboxylase \\
\hline 29842.t000024 & PFK \\
\hline $29600 . t 000017$ & aconitase \\
\hline $30131 . t 000450$ & $\mathrm{PK}$ \\
\hline 29692.t000012 & PGM \\
\hline 30171.t000020 & UGP1 \\
\hline 27914.t000023 & IDH \\
\hline $30226 . t 000050$ & $\mathrm{CS}$ \\
\hline
\end{tabular}

Fig. 4 Hierarchical clustering analysis of the proteomic and transcriptomic data. a Heatmap of all 1416 quantified protein species and their corresponding mRNAs. b Heatmap of all 173 DAPs and their corresponding mRNAs. c, d, e Heatmap of the protein species and corresponding mRNAs related to ribosome biogenesis, protein metabolic process, and carbohydrate metabolism. DDOST, dolichyl-diphosphooligosaccharideprotein glycosyltransferase. $\log _{2}$ fold change of protein species abundance (left) and gene expression (right) between ZB107 and ZB306 is presented with different colors: red represents up-regulated and green represents down-regulated

addition, the protein species abundances of the $26 \mathrm{~S}$ protease regulatory subunit $(29,739 . t 000101)$ and xylem serine proteinase $(29,172 . t 000012$ and 29,986.t000074) associated with the protein metabolic process were also decreased in ZB306 (Table 1 and Fig. 4d). Taken together, the protein species abundances of these enzymes involved in carbohydrate and protein metabolism were lower in small-seed ZB306 than in large-seed ZB107. These results suggested that greater energy and storage reserves are needed for larger seed during the process of embryogenesis and endosperm genesis, resulting in a higher seed weight and larger seed size of ZB107.

Furthermore, we compared the protein species identified in this study with the set of protein species previously reported by Houston et al. [6] (a study that generated 522 protein species in developing seeds using two-dimensional gel electrophoresis) and Nogueira et al. (a study that identified 766 and 416 protein species from 
nucellus and endosperm at different developmental stages, respectively) [18, 22]. A total of 242 protein species were presented in both Houston's study (using whole seeds, denoted as "Seed") and our study as shown in Fig. 5. There was an overlap of 302 protein species between our data and Nogueira's study (only using the endosperm of castor seed, denoted as "Endosperm"), and there was an overlap of 281 protein species between our study and the Nogueira's research of nucellus (denoted as "Nucellus"). Of note is that a total of 866 new protein species were detected in our study. These protein species were associated with embryogenesis (late embryogenesis abundant protein, 30,128.t000107/29889.t000167), seed coat development (cellulose synthase A catalytic subunit $6,29,848 . t 000205)$, seed storage proteins synthesis (2S albumin precursor, 28,166.t000037/28166.t000041/ 28166.t000042), and fatty acid synthesis (Long-chainfatty-acid CoA ligase, 29,732.t000015/29908.t000237) (Additional file 8: Table S5). Furthermore, protein species involved in plant hormone signal transduction pathways also played prominent roles in the embryogenesis/ endosperm genesis processes, such as indole-3-acetic acid (IAA)-amido synthetase GH3.5 (28,355.t000001), ARP $(30,190 . t 000561)$, and so on. These results demonstrate that proteomic analysis is not only capable of both providing a holistic understanding of seed development in castor bean and identifying the largest number of protein species that play crucial roles in the regulation of embryogenesis and endosperm genesis, but also capable of leading us to further important insights into the accumulation of storage products. Most previous studies only used part of the seed, while our study included the whole seeds of ZB107 and ZB306 at three different developmental stages. Taken together, our comparative proteomic analyses revealed that the protein species that participated in seed size variation were enriched by carbohydrate metabolism and protein synthesis during seed embryogenesis and endosperm genesis. This provided a more comprehensive understanding of the molecular basis that underlies seed size control in castor bean.

\section{Comparative transcriptomic analysis of large-seed ZB107 and small-seed ZB306}

To investigate the differences in global gene expression during the formation of seed size, RNA-seq analysis was performed using large-seed ZB107 and small-seed ZB306. A total of 49.18 million and 50.65 million highquality reads from ZB107 and ZB306 were generated, and 79.16 and $84.78 \%$ clean reads were mapped to the reference genome of castor bean, respectively. All the uniquely mapped reads were transformed into RPKM to determine the expression level of each transcript, and a total of 9545 DEGs between ZB107 and ZB306 were identified, including 1713 up-regulated and 7832 downregulated genes in ZB306 compared to ZB107 (Fig. 3c). $386,238,163,384$, and 242 DEGs were enriched in the KEGG pathways of carbohydrate metabolism, amino acid metabolism, lipid metabolism, translation, and signal transduction, respectively (Fig. 3d). Carbohydrate

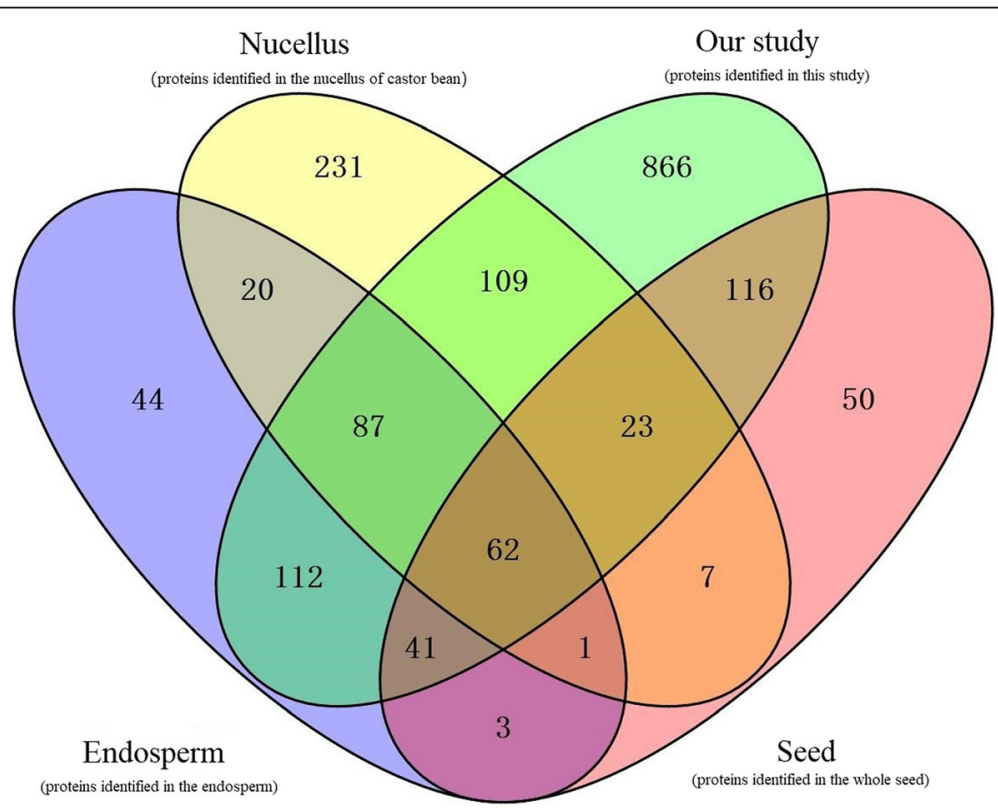

Fig. 5 Venn diagram showing the number of protein species identified in previous and current studies. Our study represents the protein species identified in this study; Seed represents protein species identified by Houston et al. [6]; Nucellus and Endosperm represent protein species identified by Nogueira et al. [18, 22] 
and amino acid metabolism were the foremost processes during seed development [14]. Most DEGs involved in the two processes were down-regulated in small-seed ZB306 compared to large-seed ZB107 (Fig. 4 and Additional file 7: Figure S3). For example, the four genes that encode sucrose syntheses (SUS, 29726.t000198, 29, 739.t000129, 29,951.t000003, and 29,660.t000014) and are involved in the carbohydrate metabolism process were identified, and three of them showed up-regulation in large-seed ZB107. The higher expression levels of SUS suggested that the content of hexoses is higher in large-seed ZB107 than in small-seed ZB306. It is likely that sugar metabolism in the developing castor bean seeds has many vital functions, such as supplying carbon to the developing endosperm, controlling cell division, or regulating cell differentiation. In addition, the DEGs involved in translation and protein metabolic process were also up-regulated in large-seed ZB107 (see in Fig. 4c and d), such as SRPL32 (29,070.t000002), SRPL8 (29, 743.t000009), eIF-5A (29,687.t000001), and Sadenosylmethionine synthetase (SAMS, 30076.t000140, 30,078.t000071, 30,128.t000431). The eIF-5A protein is originally identified as a translation initiation factor, functionally involved in the regulation of cell proliferation, cell growth and cell death [23, 24]. The SAMS is functionally involved in the regulation of methionine metabolism and carbon metabolism [25, 26]. Furthermore, GO enrichment analysis of DEGs showed that 59, 17,23 , and 21 DEGs were enriched under GO terms of cell development (GO:0048468), cell division (GO: 0051301), cell growth (GO:0016049), and cell cycle process (GO:0022402), which were associated with cell size and cell number (Fig. 6). Under the cell division term, the gene expression level of kinesin (29, 171.t000006) was 5.85-fold lower in ZB306 than in ZB107, while chitin-inducible gibberellin-responsive protein (CIGR, 29661.t000025) and eIF-5A (29,687.t000001) showed 2.19-fold and 1.30-fold down-regulation in ZB306 (Fig. 6b). The CIGR (a member of the GRAS family) is functionally involved in the regulation of cell division, elongation and expansion during seed development [27]. Furthermore, the transcript abundance of TRANSPARENT TESTA 1 protein (TT1, 30, 169.t000194) as well as the protein COBRA precursor $(29,889 . t 000012)$ was 4.49 -fold and 3.45 -fold lower in ZB306 than ZB107 in the process of cell development (Fig. 6a and c). The COBRA, encoding a putative glycosylphosphatidylinositol-anchored protein, is functionally involved in regulating cellulose synthesis, participated in the formation of plant cell wall [28]. Additionally, the conserved regulators of cell cycle, such as cyclin A (29,648.t000086, 29,794.t000196, 29, 841.t000018, 30,170.t000189, 28,152.t000004), cyclin B $(29,830 . t 000050, \quad 30,180 . t 000011,30,170 . t 000774, \quad 29$, 785.t000026), and cyclin D (30,027.t000037, 29, 908.t000283， 29,168.t000023， 30,170.t000158, 29, 801.t000066, 30,099.t000113, 29,970.t000009), were also down-regulated in ZB306 (Fig. 6d). Clearly, most of the genes involved in cell division were down-regulated in small-seed ZB306, which strongly suggested that cell number is a critical factor in the regulation of seed size/ weight in castor bean.

Plant hormones usually play critical roles in controlling plant growth and development in diverse processes [29]. In the auxin-signaling pathway, the gene that encodes auxin receptors transport inhibitor response 1 protein (TIR1, 29,908.t000274) showed a 2.42-fold higher expression in ZB107. Similarly, genes that encode auxin/indole-3-acetic acid (AUX|IAA, 28179.t000006) and GH3 $(28,152 . t 000001)$ increased 2.03 and 1.80-fold in ZB107 compared with ZB306 (in Table 2 and Fig. 7). However, the expression level of ARF2 (auxin response factor 2, 29,647.t000040) was found to be significantly higher in ZB306. Consistently, the gene expression of AHP4 (Arabidopsis histidine-containing phosphotransfer protein 4, 29,912.t000167) in cytokinins signaling pathway was up-regulated in small-seed ZB306 (Fig. 7). However, the gene expression of BRI1 interacting proteins in the signaling pathways of brassinosteroids (BRs), such as BRI1-associated receptor kinase 1 (BAK1, 30, 190.t000257), BRI1 kinase inhibitor 1 (BKI1, 30, 170.t000310), and BR-signaling kinase (BSK, 3019 0.t000453), all exhibited decreased transcript abundances in ZB306 compared to ZB107 (in Fig. 7). Overall, these observations suggest that plant hormones, i.e., auxin, cytokinin and BR, exert strong influences on the seed development process, which may be an important reason for the difference in seed size between ZB107 and ZB306. To explore the rationale of plant hormones on seed development, we performed a comprehensive ciselement analysis for the promoters of all 41 genes involved in hormone signal transduction pathways. We observed that numerous cis-elements involved in response to auxin, ABA, GA, MeJA, and SA signals were identified in the promoter regions of these genes. In particular, ten of these genes contained cis-elements functionally involved in regulating seed development (such as endosperm-specific expression, seed-specific regulation and cell cycle regulation) (Additional file 9: Figure S4). These cis-elements might be related to regulate gene expression in controlling the formation of seed size. Overall, comparative transcriptomic results indicated that cell division was responsible for the higher cell number and larger seed volume in ZB107, while the processes of carbon and protein substance metabolism, as well as hormone signal transduction during embryogenesis/endosperm genesis, were associated with the higher seed weight of ZB107. 


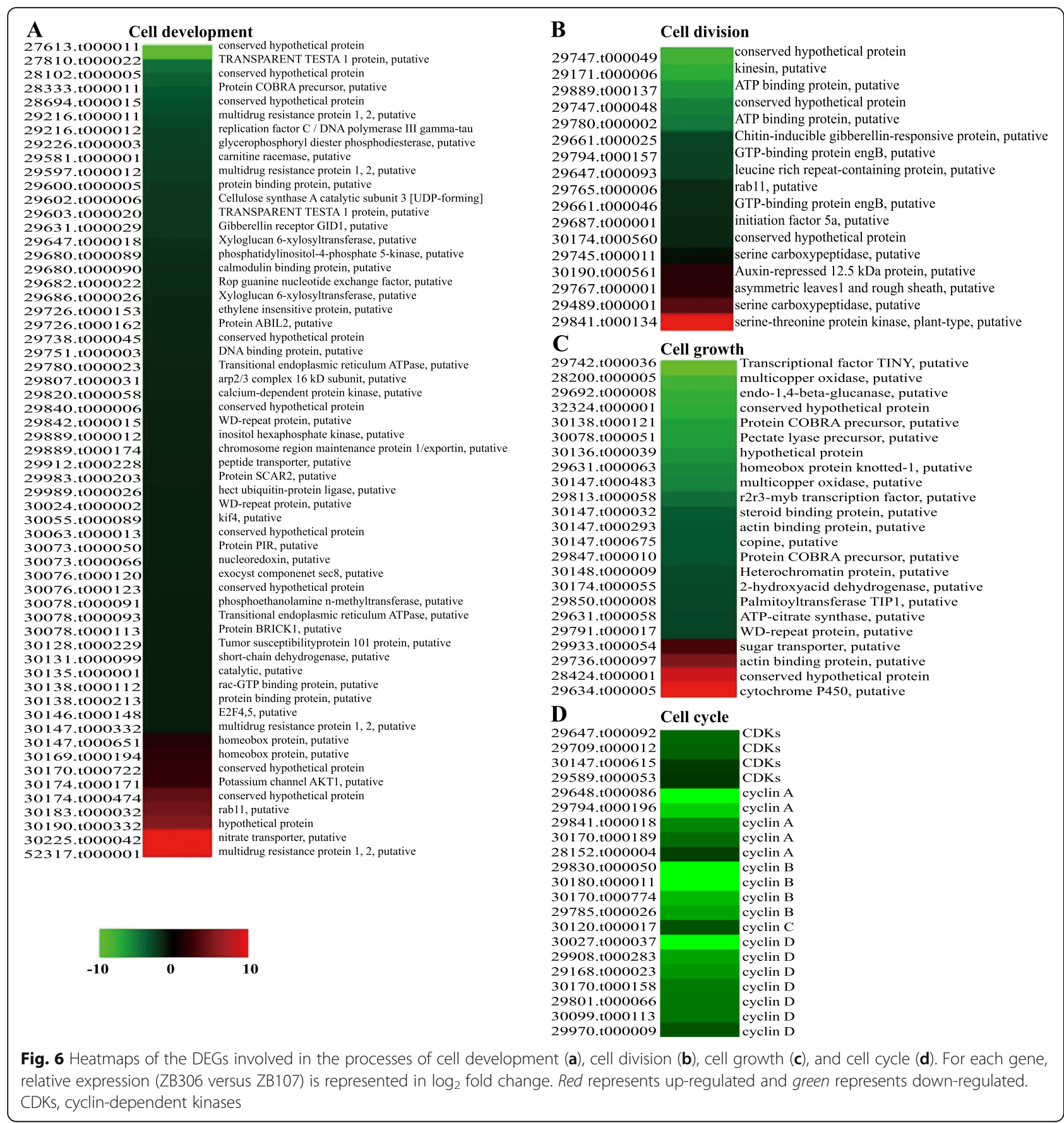

\section{Correlations between proteome and transcriptome data} A global correlation analysis between DAPs and their corresponding transcripts was conducted, resulting in a low Pearson correlation coefficient ( $r=0.334, P=2 \mathrm{e}-04$ ) (Fig. 8). The scatter plot analysis showed that 12 genes (indicated by the purple dot) were up-regulated at both the transcript and protein levels, while 68 genes (indicated by the blue dot) were down-regulated in small-seed ZB306 (Additional file 10: Table S6). These observations revealed that protein species abundances were determined by the corresponding mRNA expression levels, reflecting a strong correlation between transcripts and protein species. Among these downregulated genes at both mRNA and protein levels, 15 genes were involved in carbohydrate metabolism (Additional file 11: Figure S5), such as CS (30,226.t000050), SUS (29, 739.t000129), and pyruvate kinase (30,131.t000450); and 12 genes were related to protein metabolism, e.g., SRPL32 (29, 070.t000002), SRPL8 (29,743.t000009), and SAMS (30, 078.t000071). Our results clearly indicated that these genes involved in carbohydrate and protein metabolism were 
Table 2 Gene expression of plant hormones related genes

\begin{tabular}{|c|c|c|c|c|c|c|c|}
\hline Pathway & Gene name & Gene ID & $\begin{array}{l}\text { ZB107 } \\
\text { (RPKM) }\end{array}$ & $\begin{array}{l}\text { ZB306 } \\
\text { (RPKM) }\end{array}$ & $\log 2 \mathrm{FC}$ & P-value & FDR \\
\hline \multirow[t]{10}{*}{ Auxin } & AUX1 & $29,741 . t 000002$ & 0.86 & 3.68 & 2.1 & $9.58 \mathrm{E}-20$ & $2.23 \mathrm{E}-19$ \\
\hline & $A \cup X 1$ & $28,883 . t 000036$ & 80.12 & 0.86 & -6.54 & 0 & 0 \\
\hline & TIR1 & $29,908 \cdot t 000274$ & 30.59 & 5.71 & -2.42 & 9.34E-230 & 1.07E-228 \\
\hline & $A \cup X \mid I A A$ & $29,844 . t 000020$ & 1.26 & 3.45 & 1.46 & $3.59 \mathrm{E}-05$ & 5.60E-05 \\
\hline & AUXIIAA & $28,179 . t 000006$ & 232.36 & 56.82 & -2.03 & 0 & 0 \\
\hline & ARF10 & $27,538 . t 000014$ & 74.25 & 12.3 & -2.59 & 0 & 0 \\
\hline & ARF2 & $29,647 . t 000040$ & 21.7 & 74.29 & 1.78 & 0 & 0 \\
\hline & $\mathrm{GH} 3$ & $28,152 . t 000001$ & 394.07 & 113.06 & -1.8 & 0 & 0 \\
\hline & SAUR & 29,838.t000091 & 0.18 & 43.59 & 7.92 & $2.44 \mathrm{E}-139$ & $1.84 \mathrm{E}-138$ \\
\hline & SAUR & 29,739.t000134 & 40.68 & 12.65 & -1.69 & $5.39 \mathrm{E}-50$ & $1.95 E-49$ \\
\hline \multirow[t]{5}{*}{ CTK } & CRE1 & $29,005 . t 000011$ & 101.67 & 2.08 & -5.61 & 0 & 0 \\
\hline & AHP4 & 29,912.t000167 & 18.47 & 120.46 & 2.71 & $6.50 \mathrm{E}-248$ & $8.01 \mathrm{E}-247$ \\
\hline & AHP1 & $29,726 . t 000066$ & 91.15 & 26.59 & -1.78 & 3.85E-113 & $2.44 \mathrm{E}-112$ \\
\hline & B-ARR & $29,950 . t 000033$ & 21.97 & 0.44 & -5.63 & $4.71 \mathrm{E}-215$ & $5.11 \mathrm{E}-214$ \\
\hline & A-ARR & $29,908 . t 000174$ & 47.41 & 20.25 & -1.23 & $2.01 \mathrm{E}-51$ & $7.43 \mathrm{E}-51$ \\
\hline \multirow[t]{3}{*}{ GA } & GID1 & $29,686 . t 000008$ & 28.97 & 3.86 & -2.91 & $2.58 \mathrm{E}-142$ & $1.97 \mathrm{E}-141$ \\
\hline & GID2 & $30,170 . t 000622$ & 40.12 & 12.36 & -1.70 & $3.00 \mathrm{E}-55$ & $1.16 \mathrm{E}-54$ \\
\hline & DELLA & $29,807 . t 000012$ & 71.54 & 8.52 & -3.07 & 0 & 0 \\
\hline \multirow[t]{5}{*}{ ABA } & $\mathrm{PP} 2 \mathrm{C}$ & $30,075 . t 000035$ & 0.07 & 273.45 & 12.01 & 0 & 0 \\
\hline & PP2C & $30,128 . t 000337$ & 69.77 & 14.66 & -2.25 & 0 & 0 \\
\hline & SnRK2 & $28,725 . t 000009$ & 175.59 & 66.55 & -1.40 & 0 & 0 \\
\hline & SnRK2 & 29,908.t000118 & 10.86 & 22.02 & 1.02 & $3.62 E-27$ & $9.62 E-27$ \\
\hline & $A B F$ & 29,801.t000121 & 55.02 & 15.19 & -1.86 & 1.35E-201 & $1.39 \mathrm{E}-200$ \\
\hline \multirow[t]{9}{*}{ Ethylene } & ETR & 28,802.t000007 & 49.56 & 19.23 & -1.37 & $1.09 \mathrm{E}-198$ & 1.10E-197 \\
\hline & ETR & $29,680 \cdot t 000086$ & 21.25 & 87.53 & 2.04 & $2.69 \mathrm{E}-155$ & $2.20 \mathrm{E}-154$ \\
\hline & CTR1 & $29,678 \cdot t 000014$ & 43.32 & 10.27 & -2.08 & $8.75 E-205$ & $9.11 \mathrm{E}-204$ \\
\hline & CTR1 & $30,147 .+000229$ & 18.26 & 38.74 & 1.09 & $1.08 \mathrm{E}-53$ & $4.08 \mathrm{E}-53$ \\
\hline & MPK6 & $29,688 \cdot t 000016$ & 47.68 & 20.31 & -1.23 & $3.95 \mathrm{E}-63$ & $1.65 \mathrm{E}-62$ \\
\hline & EIN2 & $30,078 . t 000113$ & 76.78 & 25.36 & -1.60 & 0 & 0 \\
\hline & EIN3 & 30,169.t000172 & 20.42 & 9.36 & -1.13 & $5.01 \mathrm{E}-53$ & $1.88 \mathrm{E}-52$ \\
\hline & $\mathrm{EBF} 1 / 2$ & 29,848.t000185 & 130.53 & 16.02 & -3.03 & 0 & 0 \\
\hline & ERF1/2 & $30,147 . t 000602$ & 1.74 & 0.59 & -1.56 & 0 & 0 \\
\hline \multirow[t]{9}{*}{$B R$} & BAK1 & $30,190 \cdot \mathrm{t} 000257$ & 92.68 & 5.03 & -4.20 & 0 & 0 \\
\hline & BRI1 & $29,950 \cdot t 000019$ & 0.13 & 79.08 & 9.23 & 0 & 0 \\
\hline & BRI1 & $29,820 \cdot t 000032$ & 25.76 & 0.34 & -6.23 & 0 & 0 \\
\hline & BKI1 & $30,170 \cdot t 000310$ & 5.19 & 0.55 & -3.23 & $8.68 \mathrm{E}-19$ & $1.98 \mathrm{E}-18$ \\
\hline & BSK & $30,190 \cdot t 000453$ & 42.70 & 12.11 & -1.82 & $6.44 \mathrm{E}-97$ & $3.60 \mathrm{E}-96$ \\
\hline & BSU1 & $30,128 . t 000269$ & 40.56 & 19.45 & -1.06 & $1.46 \mathrm{E}-100$ & $8.36 \mathrm{E}-100$ \\
\hline & BZR1/2 & $29,646 . t 000010$ & 120.71 & 43.54 & -1.47 & $3.29 \mathrm{E}-232$ & $3.79 \mathrm{E}-231$ \\
\hline & $\mathrm{TCH} 4$ & $30,041 . t 000001$ & 37.08 & 6.77 & -2.45 & 2.06E-91 & 1.10E-90 \\
\hline & CYCD3 & $29,168 . t 000023$ & 16.16 & 2.08 & -2.96 & 4.11E-93 & 2.23E-92 \\
\hline
\end{tabular}

RPKM, Reads Per kb per Million reads, represented the expression level of a gene 


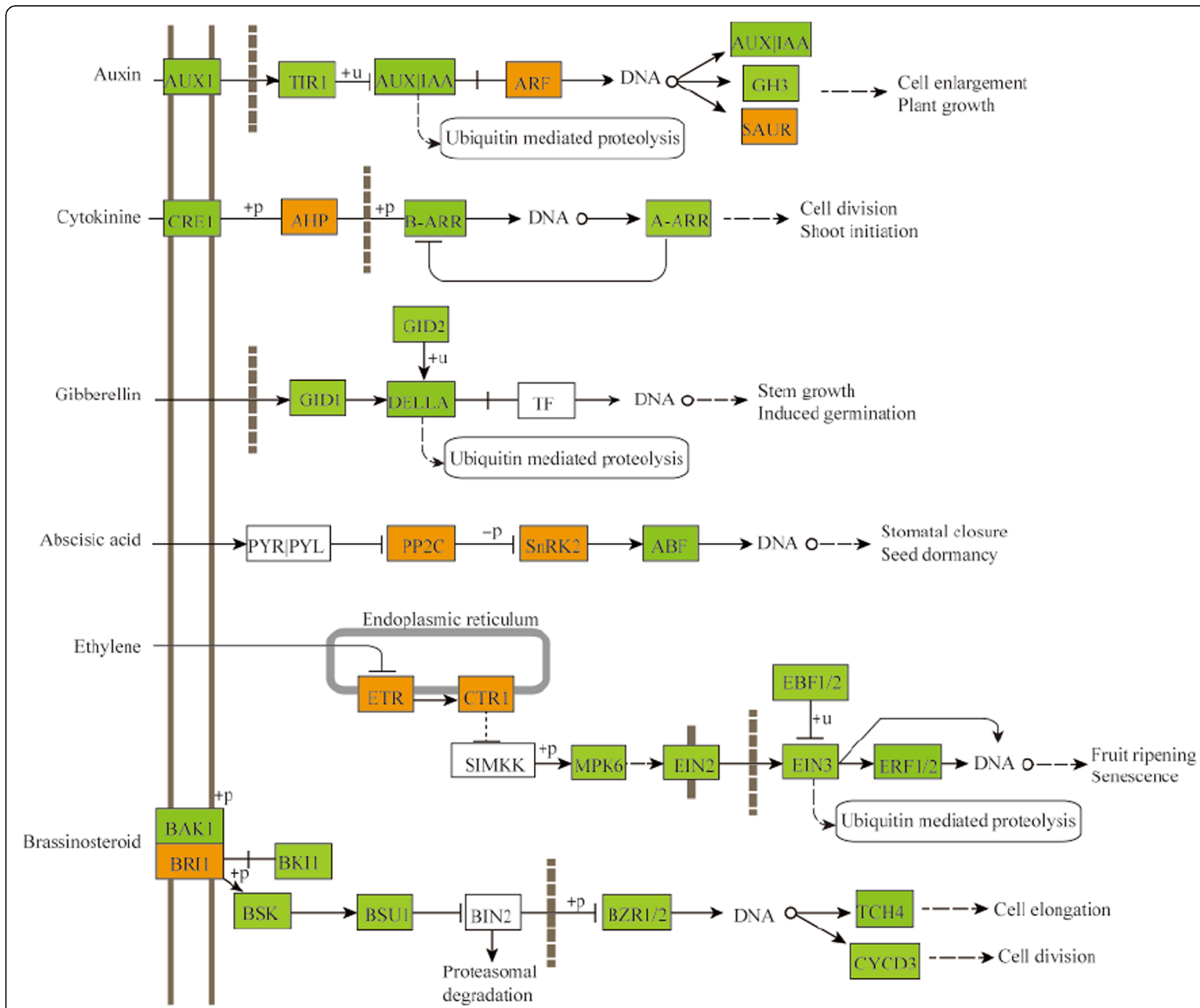

Fig. 7 DEGs involved in the plant hormone signal transduction pathways. This graph was modified from a KEGG map (ko04075) according to reference [29]. Yellow boxes represent significant up-regulated genes; green boxes represent significant down-regulated genes

coordinately regulated at both transcript and protein levels and that seed-filling affects seed size/weight. Furthermore, 40 genes showed opposite trends at the proteomic and transcriptomic levels (Additional file 10: Table S6), implying that post-transcriptional and/or post-translational modifications might play an important role in determining protein species abundances. A total of 15 genes were up-regulated in mRNA levels and decreased in protein species abundances (indicated by the red dot), while 25 genes were significantly downregulated in mRNA levels and increased in protein species abundances (indicated by the green dot in Fig. 8), e.g., SRPL12 (29,588.t000012), SRPL19 (30,167.t000025), and SRPL23 $(29,805 . t 000016)$. It is known that ribosomal proteins play critical roles in numerous essential cell activities in plants, such as controlling many developmental programs through translational regulation or post-translational modifications in Arabidopsis [30]. Thus, changes in gene expression might not always adequately reflect proteins levels, and the post-transcriptional or post-translational modifications should not be ignored. Taken together, our data indicate that the major differences between large-seed ZB107 and small-seed ZB306 were found in carbohydrate and protein metabolism at both protein and transcript levels, while the differences in post-transcriptional or post-translational modifications may also exert influence on the seed-filling process.

\section{Validation of selected DAPs/DEGs by qRT-PCR analyses}

To confirm the reliability of comparative proteomic and transcriptomic analysis, expression patterns of the 15 candidate DAPs/DEGs were detected at different developmental stages in ZB107 and ZB306 based on qRTPCR (Fig. 9). For cell division, the expression level of CYCD1;1 was significantly higher in large-seed ZB107 than in small-seed ZB306, especially at 14 DAF, which 


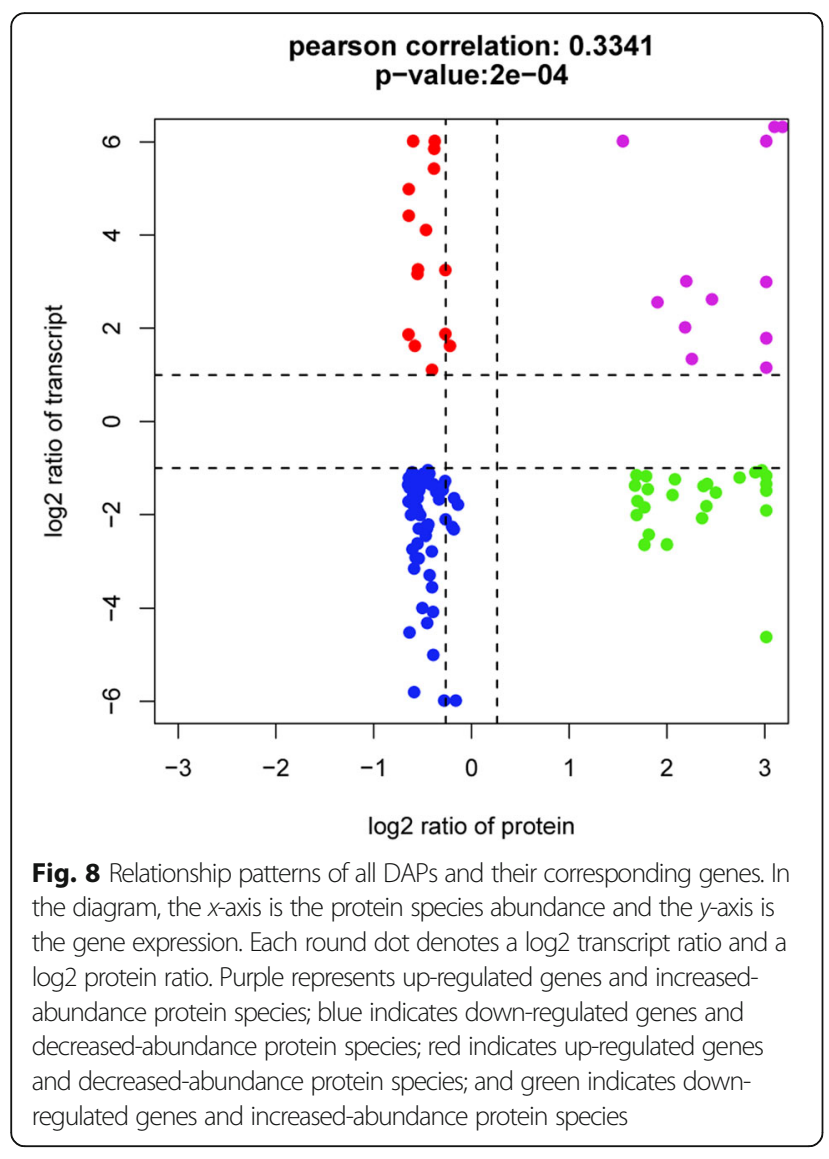

suggested that CYCD1;1 regulates cell number mainly in the early stage of seed development. Similarly, the relative gene expression of eIF-5A was significantly higher in ZB107 than ZB306 from 7 to 28 DAF, consistent with the pattern of transcriptomic and proteomic analysis. Moreover, the gene expression of ARF2 and BZR1 increased gradually, whereas the expressions of AUX|IAA and BAK1 were down-regulated in both ZB107 and ZB306 from 7 to 56 DAF. In particular, at the early stage, the expressions of AUX|IAA and BAK1 were significantly higher in ZB107 compared to ZB306 (at 7 DAF), but at the middle stage (28 DAF), the expressions of ARF2, AUX|IAA and BAK1 were significantly lower in ZB107 than that in ZB306. For carbohydrate metabolism, the expression levels of PGK (phosphoglycerate kinase) at 14 DAF were higher in ZB107 than that in ZB306, indicating that differences in seed-filling mainly occurred in the early developmental stage. For protein metabolism and synthesis, the expression levels of the SRPL23a, SRPL27a, and 26S protease regulatory subunits were higher in ZB107 than that in ZB306 at 14 DAF, while genes encoding SAMS, SRPL13, SRPL23a, and 26S protease regulatory subunits were down-regulated in ZB107 at 28 DAF, to the extent that the expressions of these genes were not always correlated with their protein species abundances. All these results not only confirm the accuracy and reliability of the DAPs/DEGs involved in seed size formation, but also further illustrate that cell division, carbohydrate metabolism, and protein synthesis enact important roles in the formation of seed size.

\section{Discussion}

Comparative analysis of proteomic techniques for protein species identification

In recent years, many proteomic studies have been conducted on the metabolic processes in castor bean seeds, e.g., we have learned more about the processes that manage carbon assimilation during the seed-filling phase of seed development, gained new insights into the biosynthesis of fatty acids, and discovered further mechanisms that are responsible for the biosynthesis of storage proteins during seed development and germination $[6,18,22$, 31]. However, our current study focuses on addressing potential mechanisms behind the formation of seed size through the comparison of protein and transcript profiles of large-seed ZB107 and small-seed ZB306 during seed development. A total of 1416 protein species were identified from developing castor seeds using the iTRAQ method combined with LC-MS/MS analysis, 866 of which were newly identified in this study. It was well known that different proteomic approaches applied for protein species identification often leaded to variable results [32]. The iTRAQ labeling method used in the present study is more sensitive and powerful than the protein fractionation of 2DGE or SDS-PAGE methods for protein species identification. Additionally, the iTRAQ method has been widely applied to investigate the potential molecular mechanisms that underlie seed development and the accumulation of storage reserves in developing seeds, such as in Arabidopsis [33], Citrus sinensis [34], and rice [35]. However, the largest number of protein species was observed in this study compared to previous studies, because the whole seeds from three different stages were used in this study. In short, our proteomic analysis will provide important information on seed development of castor bean.

\section{Proteomic identification of cell division and seed-filling related protein species}

Castor bean typically has endospermic seeds, whose size is largely determined by the endosperm volume. In this study, we discovered that the endosperm size of castor bean was dependent on cell number rather than cell size, which was similar to the determination of grain size in rice and maize [36, 37]. Our proteomic analyses reveal that cell division and diverse metabolic processes play crucial roles in controlling the different seed size of ZB107 and ZB306. In particular, we found that ARP $(30,190 . t 000561)$ exhibited different protein species abundances between largeseed ZB107 and small-seed ZB306, and it was reported 


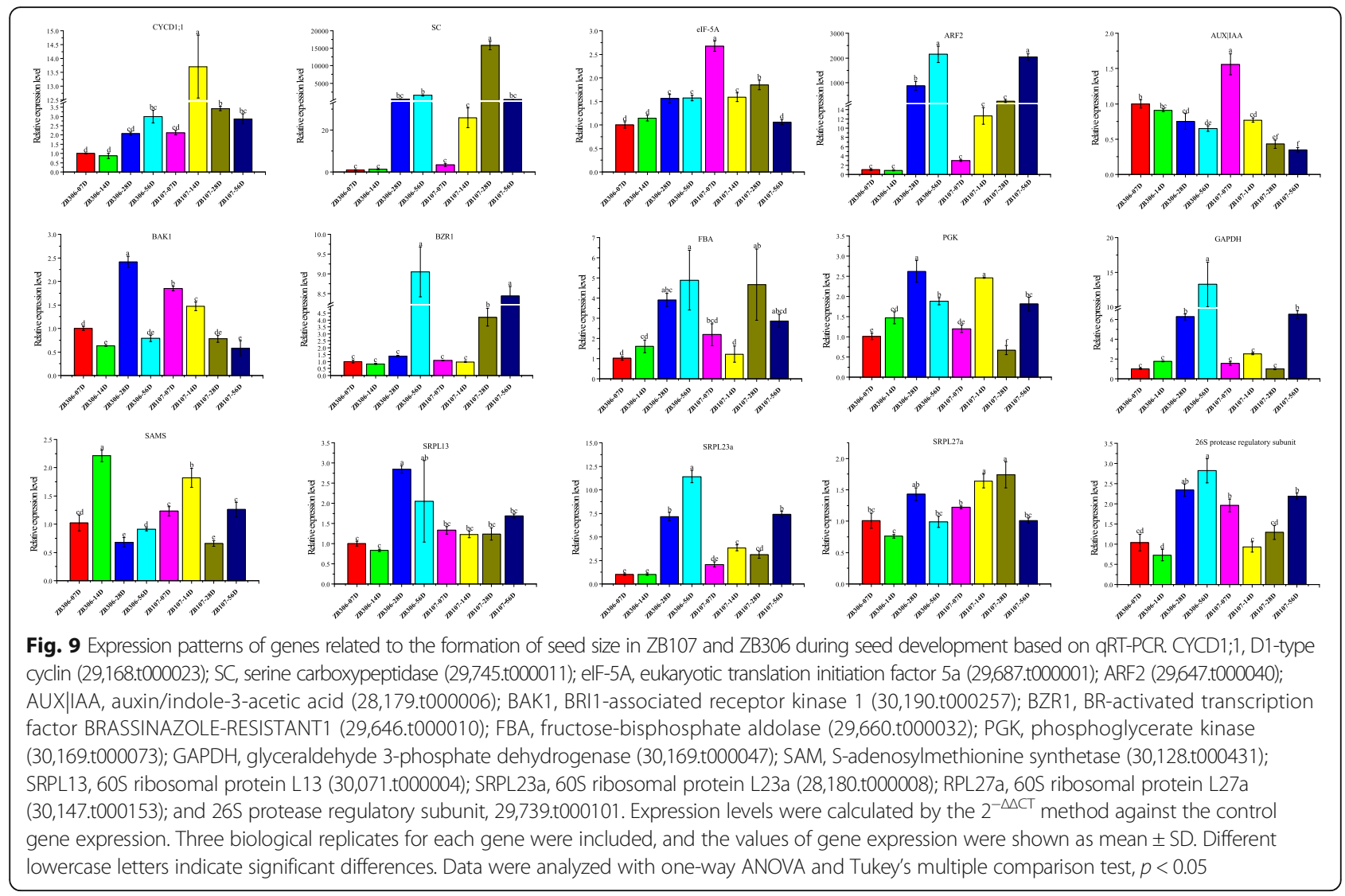

that ARP in Chinese cabbage regulated the cell division of different tissues [38]. In addition, SC (29,745.t000011) and eIF-5A (29,687.t000001) exhibited higher protein species and transcript abundances in large-seed ZB107 than small-seed ZB306, and it had been demonstrated that both $\mathrm{SC}$ and eIF-5A played critical roles in regulating cell division and controlling cell cycles in rice [39]. Consequently, these protein species might be the putative controllers that regulate cell division and determine the formation of seed size/weight in castor bean.

It is known that primary metabolism mainly occurs during the early stage of seed development, and many protein species involved in carbohydrate and protein metabolism have been identified in this study. Central carbon metabolism (including glycolysis and TCA cycle) is a main physiological process during seed-filling [40]. A total of 18 protein species involved in carbohydrate metabolism showed higher protein species abundances in large-seed ZB107 than in small-seed ZB306. For instance, You et al. found that the protein species abundances of FBA (29, 660.t000032), PGK (30,169.t000073), and glucose-6phosphate isomerase (GPI, 30170.t000437) involved in glycolysis were higher in larger grains than smaller grains during the grain-filling period of rice [13]. Thus, the above protein species, with differential abundances in carbohydrate metabolism during seed development, might be involved in regulating the formation of seed size by affecting seed-filling in castor bean. Additionally, the seeds of castor bean contain nearly $46-55 \%$ oil by weight, and nearly $90 \%$ of the oil is hydroxy fatty acid, while several enzymes in the TCA cycle, such as aconitase, malic enzyme, and CS also participated in fatty acid metabolism through the glyoxylate cycle [41]. We identified that the GAPDH protein $(30,169 . t 000047)$, a key enzyme for activating fatty acid biosynthesis in glycolysis [42], had higher protein species abundances in large-seed ZB107 compared to small-seed ZB306. A previous study indicated that the activity and stability of GAPDH were critical in controlling lipid biosynthesis during the seed development of castor bean [43]. In addition, protein metabolism plays a critical role in regulating embryogenesis/endosperm genesis and storage protein biosynthesis [44]. We identified that the protein species abundances of SRPL13 (30,071.t000004), SRPL20 (30,147.t000462), SRPL8 (29,743.t000009), SRPL23a (28,180.t000008), and SRPL27a (30,147.t000153) were significantly increased in large-seed ZB107. Particularly, SRPL27a is critical for controlling seed development by regulating cell division and cell cycle progression in Arabidopsis [45, 46], another ribosomal L18 protein, HEART STOPPER (HES), has been shown to be essential during the early seed development of Arabidopsis via influencing cell division and cell differentiation [47]. The 
protein species abundance of the $26 \mathrm{~S}$ protease regulatory subunit (29,739.t000101) was significantly increased in ZB107, which played a pivotal role in regulating cell cycle and differentiation during embryogenesis in Arabidopsis [48]. Moreover, xylem serine proteinase (29,986.t000074), an enzyme critical in the regulation of xylem biosynthesis [49], was increased in large-seed ZB107. Likewise, xylem serine proteinase was also involved in the formation of seed coat in Arabidopsis and Glycine max [50]. Taken together, these DAPs involved in the metabolism or biosynthesis of carbohydrates, proteins, lipids, and xylem might be putative controllers directly or indirectly influencing the formation of seed size/weight in castor bean. Further research should investigate the molecular mechanisms of these proteins underlying seed size variation.

\section{Transcriptomic identification of key genes involved in seed size formation}

Comparative transcriptome analysis revealed that a total of 120 DEGs were involved in cell development, cell division, cell growth, and cell cycle control, suggesting that these genes might participate in controlling seed size through regulating cell division or cell cycle. In addition, a kinesin gene $(29,171 . t 000006)$ involved in cell division was up-regulated in large-seed ZB107, which could potentially determine seed size by the regulation of cell number in Nicotiana tabacum [51]. Similarly, TT1 (30, 169.t000194) in cell development was also up-regulated in large-seed ZB107, and it has been demonstrated that BnTT1 not only regulated flavonoid biosynthesis, but also affected seed size and fatty acid composition in Brassica napus [52, 53]. In carbohydrate metabolism, the gene expression levels of SUS (29,739.t000129, 29, 951.t000003, and 29,660.t000014) were higher, suggesting that the content of hexoses is higher in large-seed ZB107 than in small-seed ZB306. The high levels of hexoses could maintain cell division and cell expansion during the embryogenesis of Vicia faba, and overexpression of a potato SUS gene in maize seeds could increase the starch content $[54,55]$. Furthermore, it has been proved that the activity of SUS is positively correlated with seed size in chickpea [56]. Additionally, several plant hormones such as auxin, cytokinin, and BR could potentially regulate seed size through cell development (Fig. 7). For example, the expression of ARF2 $(29,647.000040)$ was lower in large-seed ZB107, and it could negatively regulate seed size via repression of cell division in the integument region of Arabidopsis seed [57]. It is likely that ARF2 may be responsible for determining seed size in castor bean via controlling the extension of the seed coat. Similarly, cytokinins have also been reported to affect seed size through maternal or zygotic tissues [58]. AHP4 (29,912.t000167) was down-regulated in largeseed ZB107, which was a negative regulator of cytokinin signaling [59]. Moreover, AHP4 has been reported to affect seed size, vascular development, and other aspects of plant development in wheat [60]. The BR-activated transcription factor BRASSINAZOLE-RESISTANT1 (BZR1, 29,646.t000 010) could potentially regulate seed size and shape via influencing specific processes in the integument, endosperm, and embryo development in Arabidopsis [61]. The expression patterns of these genes involved in cell division, signal transduction of plant hormones, carbohydrate metabolism, and protein metabolism were confirmed by qRT-PCR during the seed development of ZB107 and ZB306. Hence, we suggest that the above-mentioned processes are responsible for the seed size/weight variation in castor bean.

\section{The global relationship between developing seeds proteome and transcriptome}

Recent advances in proteome and transcriptome profiling technologies have provided new opportunities to integrate protein abundance with gene expression in the analysis of the molecular mechanisms that underlie the formation of seed size in castor bean at multiple levels. The consistency between protein species abundances and mRNA expressions in carbohydrate and protein metabolism indicates that gene expression determines the corresponding protein species abundances. In the process of protein metabolism, highly expressed genes, SAMS (30,078.t000071/ 30128.t000431), were always rich in protein species abundances and their transcript levels and protein species abundances were higher in large-seed ZB107 compared to small-seed ZB306 (Fig. 4d). A previous study showed that overexpression of SAMS in transgenic tobacco increased the number and weight of seeds [62]. Occasionally, there is a poor correlation between protein species abundances and mRNA levels, which has been demonstrated in previous studies of developing cotton fibers, and highlights the importance of post-transcriptional and/or posttranslational regulation [63]. Post-transcriptional and post-translational modifications could impact transcript and protein stability [64] as well as influence the translation and metabolism processes. Ribosomal proteins played an essential role in translation, and several ribosomal proteins were the targets of post-translational modifications, which led to the inconsistency of mRNA levels and protein species abundances [65]. For example, the protein species abundances of SRPS12/19/23 were increased in small-seed ZB306 compared to large-seed ZB107, while their gene expressions exhibited the opposite pattern (Fig. 4c). So far, almost no research has focused on how posttranscriptional modifications and/or post-translational modifications affect seed size. In future studies, numerous post-transcriptional and post-translational regulatory processes should be considered when referring to the proteomics of the molecular basis behind seed development. 


\section{Conclusions}

Castor bean seeds are typically endospermic in dicotyledons because of their persistent endosperms in maturity. In this study, histological observation revealed that seed size was determined by cell number rather than cell size at the cellular level in the endosperm of castor bean. Combining with comparative transcriptomic and proteomic analyses of developing seeds from two inbred varieties of large-seed ZB107 and small-seed ZB306, we identified that most of DAPs/DEGs were functionally involved in cell division and storage reservoir accumulation, consistent with the formation of seed size in volume and weight. These identified DAPs/DEGs may play a critical role in governing the formation of seed size in castor bean. The correlative analysis between proteomic and transcriptomic data showed that many genes involved in cell division, carbohydrate metabolism, and protein metabolism were correlatively regulated at both transcript and protein levels, though the Pearson correlation coefficient was low $(r=0.334)$. These data could provide a crucial resource to further understand the molecular mechanisms governing seed size/weight in endospermic seeds of castor bean. We hope this research will help us to unravel the genetic foundation in the improvement of crop yields by increasing the seed size.

\section{Methods}

\section{Plant materials and sampling}

The seeds of castor bean elite inbred lines ZB107 (largeseed) and ZB306 (small-seed) were the primary materials in this study. ZB107 and ZB306 were both grown in the Xishuangbanna Tropical Botanical Garden of the Chinese Academy of Science (Menglun Town, Mengla County, Yunnan Province, China; $21^{\circ} 56^{\prime} \mathrm{N}, 101^{\circ} 15^{\prime} \mathrm{E}, 600 \mathrm{~m}$ elevation). This region is characterized by an average temperature of $21^{\circ} \mathrm{C} \sim 22^{\circ} \mathrm{C}$. The seeds of ZB107 were collected 7, 21, 35, 49, and $63 \mathrm{DAF}$, corresponding to ZB306 at 7, 14, 28, 42, and 56 DAF. Each time, at least twenty seeds from five independent plants were used for experiments, and the same tests were performed across three biological replicates. Samples for iTRAQ and RNAseq analyses were immediately frozen in liquid nitrogen and stored at $-80^{\circ} \mathrm{C}$, while the remaining samples were used for measuring fresh and dry weight.

\section{Seed weight and protein content measurements}

The individual seeds of all harvested materials were immediately weighed for average fresh weight using an analytical balance (TP-214; Denver Instrument, USA), while average dry weight of individual seeds was measured after drying samples at $65^{\circ} \mathrm{C}$ for $48 \mathrm{~h}$ in an oven. Protein content was determined on the basis of dry mass using a Kjelmaster K-375 Automatic Steam Distillation
System as previously described [66]. Three seeds from three independent plants were successively used to examine the FW, DW, and protein content as one biological replicate and average values were calculated from three biological replicates.

\section{Morphological and cellular analysis}

To determine seed size, we photographed the projective area of mature dry seeds and endosperm. Ten seeds were freshly isolated from five independent plants of ZB107 at 63 DAF and ZB306 at 56 DAF. Seed coat and embryo were both dissected from seeds in order to measure the cell size of the endosperm. Endosperms were trimmed into appropriately sized samples, fixed in a formaldehydeacetic acid solution for no less than $48 \mathrm{~h}$ at room temperature, dehydrated in a series of ethanol in ascending concentration, cleared in xylene, and embedded in paraffin as previously described by Nogueira et al. [18] with some modifications. Each endosperm was divided into internal, middle, and external parts to measure cell size, and each part was sectioned at $5 \sim 10 \mu \mathrm{m}$ thickness under a CM3050S rotary microtome (Leica, Germany). These sections were stained with $0.05 \%$ toluidine blue to visualize the cell size on a Leica microscope (DM5500B, Bensheim, Germany). At least twenty images from three parts of the endosperm were photographed using Leica Microsystems (DFC450C). Endosperm area and endosperm cell area were analyzed using Image J software.

\section{Protein preparation and iTRAQ labeling}

We used whole developing seeds of ZB107 at 21, 35, and 63 DAF as well as ZB306 at 14, 28, and 56 DAF for further proteomics analysis (Additional file 12: Figure S6). Proteins were extracted from each sample with three independent replicates. Protein concentration was determined by 2D Quant kit (GE Healthcare), and verified using SDS-PAGE. Equal amounts of three protein samples from ZB107 were mixed as 'large-seed', and equal amounts of three protein samples from ZB306 were mixed as 'small-seed'. The protein samples $(100 \mu \mathrm{g})$ of large-seed ZB107 samples and small-seed ZB306 samples were digested with trypsin, then the peptides were labeled with 117 and 121 tags, respectively, using 8-plex iTRAQ reagents. All samples were pooled with equal fractions and dried in a vacuum centrifuge.

\section{SCX fractionation}

The iTRAQ-labeled peptides were fractionated using Agilent 1200 HPLC with strong cation exchange (SCX) chromatography. The dried iTRAQ-labeled peptides were diluted in buffer $\mathrm{A}\left(10 \mathrm{mM} \mathrm{K \textrm {H } _ { 2 }} \mathrm{PO}_{4}, 25 \% \mathrm{ACN}\right.$, $\mathrm{pH}$ 3.0). The HPLC was performed at a flow rate of 1.0 $\mathrm{mL} / \mathrm{min}$ with a $50 \mathrm{~min} \mathrm{HPLC}$ gradient consisting of $100 \%$ buffer A for $5 \mathrm{~min}, 0 \sim 20 \%$ buffer B (10 mM 
$\left.\mathrm{KH}_{2} \mathrm{PO}_{4}, 25 \% \mathrm{ACN}, 500 \mathrm{mM} \mathrm{KCL}, \mathrm{pH} 3.0\right)$ for $15 \mathrm{~min}$, $20 \% \sim 40 \%$ buffer B for 10 min, 40\% 100\% buffer B for $10 \mathrm{~min}$, and $100 \%$ buffer A for $10 \mathrm{~min}$. The eluted peptides were collected and combined into twelve fractions. Each fraction was dried in a vacuum dryer and resuspended in $0.1 \%$ formic acid (FA) for LC-MS/MS analysis.

\section{LC-MS/MS analysis}

The LC fractions were analyzed using a Triple TOF 5600 mass spectrometer system equipped with nanoflow reversed-phase liquid chromatography (RPLC) system (AB SCIEX). The peptide fractions were loaded onto a nanobored $\mathrm{C} 18$ column at a flow rate of $0.20 \mu \mathrm{L} / \mathrm{min}$. An elution gradient of 5\% 40\% ACN (0.1\% FA) within a $120 \mathrm{~min}$ gradient was used. The mass spectroscopy data were acquired using an ion spray voltage of $2.5 \mathrm{kV}$, curtain gas of 30 PSI, nebulizer gas of 5 PSI, and an interface heater temperature of $150{ }^{\circ} \mathrm{C}$. We used an information-dependent acquisition (IDA) mode to acquire MS/MS data. Survey scans were acquired in 250 ms intervals, and as many as 35 product ion scans were collected with a $20 \mathrm{~s}$ exclusion window and a total cycle time of $2.5 \mathrm{~s}$. A rolling collision energy setting was applied to all precursor ions for CID. The data acquisition rate was $4 \mathrm{~s}$ per spectrum.

\section{Proteomic data analysis}

The raw data were converted into MGF files using Proteome Discoverer software (Thermo Scientific, USA). The identification of protein species was performed using the Mascot software (Matrix Science) against the Ricinus communis database (ftp://ftp.tigr.org/pub/data/castorbean/release_0.1/). The following criteria were applied: iTRAQ 8plex was chosen for quantification with unique peptides, peptide mass tolerance value was set at $20 \mathrm{ppm}$, and the tolerance of MS/MS was set at $0.6 \mathrm{Da}$. The quantitative protein species ratios were calculated and normalized by the median ratio of only unique peptides. For the quantification of protein species, a mass-to-charge ratio $(\mathrm{m} / \mathrm{z})$ of 117 was performed as the control sample in accordance with the peak area of $\mathrm{m} / \mathrm{z} 121$ reporter ions. A sequest score of $\mathrm{HT}>0$ for authentic proteins and $\geq 1$ for unique peptides were used as the screening criteria. The miss values were maintained with the null values. Protein species with a fold change $\geq 1.5$ or $\leq 0.67$ and a $p$-value $<0.05$ in all three replicates were determined as differentially abundant protein species (DAPs).

The functions of all the protein species were annotated using the NCBI $\mathrm{nr}$ and SwissProt/Uniprot databases and further analyzed using the Cluster of Orthologous Groups of proteins (COG), Gene Ontology (GO), and the Kyoto Encyclopedia of Genes and Genomes (KEGG) databases. These identified DAPs were subjected to GO and KEGG enrichment analyses. Hierarchical clustering of protein species between the two samples was visualized using MeV 4.9.0 software.

\section{Transcriptome sequencing and data analysis}

Total RNA was extracted from the same samples used for the proteomics analysis with the RNAprep Pure Plant Kit (Tiangen, Beijing, China). RNA concentration and integrity were measured using the Agilent 2100 Bioanalyzer (Agilent Technology, USA). Two RNA-seq libraries (ZB107 and ZB306) were constructed and sequenced on an Illumina HiSeq 2000 platform. After removing low-quality reads, the sequencing data were mapped to the castor bean reference genome using SOAP2 with default parameters [67]. Reads per kilobase of exon model per million mapped reads (RPKM) were used to estimate the expression levels of genes. Differentially expressed genes (DEGs) between ZB306 and ZB107 were identified with a FDR $\leq 0.01$ and $\mid \log 2$ (fold change) $\mid \geq 1$. GO and KEGG Pathway enrichment analysis for DEGs were carried out by Omicshare Tools (http://www.omicshare.com/tools/Home/Soft/getsoft).

To identify the cis-elements in the promoter of genes involved in the hormone signal transduction pathways, $1500 \mathrm{bp}$ upstream sequences of genes were extracted from reference genome and cis-elements were detected by querying the PlantCARE database (http://bioinformatics.psb.ugent.be/webtools/plantcare/html/).

\section{Correlation analyses of transcriptome and proteome}

To investigate the concordance between transcriptome and proteome during the seed development of ZB107 and ZB306, a correlation analysis was performed based on DAPs and their corresponding transcripts. The Pearson's correlation coefficient was calculated for these data and scatter plots were created with the $\log 2$-transformed ratios of transcripts and corresponding protein species abundances.

\section{qRT-PCR validation}

We selected fifteen genes to validate their expression patterns in the ZB306 and ZB107 seeds when at different developmental stages using qRT-PCR. Total RNAs were extracted independently from eight samples, including the seeds of ZB306 at 7, 14, 28, and 56 DAF along with the corresponding seeds of ZB107 at 7, 21, 35, and 63 DAF. At this stage, to facilitate the description of the seed development periods, we used the period of ZB306 to represent the corresponding developmental period of ZB107. The cDNA was synthesized with $1 \mu \mathrm{g}$ total RNA using the TransScript All-in-One First-Strand cDNA Synthesis SuperMix for qPCR kit (TransGen Biotech, Beijing, China), and qRT-PCR was carried out according to our previous studies [21]. We performed testing 
across three biological replicates for each gene and each experiment. The relative expression values for each gene in each RNA sample were mean \pm SD. The primers used for qRT-PCR were designed using Primer 3 web and were presented in Additional file 13: Table S7.

\section{Statistical analysis}

For all statistical significance analyses, at least three biological replicates were used for ZB107 and ZB306. Student's $t$-test and one-way analysis of variance (ANOVA) followed by Tukey's multiple comparison test $(P<0.05)$ was performed using SPSS18.0. The following asterisks indicate the results of significance testing: ${ }^{*} p<0.05$ and ** $p<0.01$. Different lowercase letters in the graphs indicate significant differences. Data represent mean values and error bars are SD.

\section{Supplementary information}

Supplementary information accompanies this paper at https://doi.org/10. 1186/s12870-020-2249-1.

\begin{abstract}
Additional file 1: Table S1. Numbers of spectra, peptides, and protein species identified in the ITRAQ analysis

Additional file 2: Table S2. Peptide sequences of the identified protein
\end{abstract} species (XLS 904 kb)

Additional file 3: Figure S1. The COG functional category analysis of all proteins.

Additional file 4: Table S3. Eight protein species involved in cell cycle control, cell division, chromosome partitioning

Additional file 5: Figure S2. GO categories for all protein species identify in both ZB107 and ZB306.

Additional file 6: Table S4. Total list of the differentially abundant protein species (XLS $128 \mathrm{~kb}$ )

Additional file 7: Figure S3. Schematic representation of the DAPs and DEGs involved in carbohydrate metabolism of castor bean seed.

Additional file 8: Table S5. Gene functional classes of protein species only detected in our comparative proteomics

Additional file 9: Figure S4. Cis-element analysis of promoter sequences of genes in hormone signal transduction pathways.

Additional file 10: Table S6. Correlation analysis of the DAPs and the corresponding genes

Additional file 11: Figure S5. The KEGG annotation of genes that were correlated between protein and transcript levels.

Additional file 12: Figure S6. Workflow of identify DAPs/DEGs between large-seed ZB107 and small-seed ZB306.

Additional file 13: Table S7. Summary of primers used in this study.

\section{Abbreviations}

AHP4: Arabidopsis histidine-containing phosphotransfer protein 4; ARF2: Auxin response factor 2; ARP: Auxin-repressed $12.5 \mathrm{kDa}$ protein; AUXIIAA: Auxin/indole-3-acetic acid; BAK1: BRI1-associated receptor kinase 1; BRs: Brassinosteroids; BSK: BR-signaling kinase; BZR1: BRASSINAZOLERESISTANT1; CIGR: Chitin-inducible gibberellin-responsive protein; COG: Cluster of Orthologous Groups of proteins; CS: Citrate synthase; DAF: Days after fertilization; DAPs: Differentially abundant protein species; DEGs: Differentially expressed genes; DW: Dry weight; elF-5A: Eukaryotic translation initiation factor 5a; FA: Formic acid; FBA: Fructose-bisphosphate aldolase; FW: Fresh weight; GAPDH: Glyceraldehyde 3-phosphate dehydrogenase; GO: Gene Ontology; GPI: Glucose-6-phosphate isomerase; IDA: Information-dependent acquisition; iTRAQ: Isobaric tags for relative and absolute quantification; KEGG: Kyoto Encyclopedia of Genes and Genomes; PGK: Phosphoglycerate kinase; PGM: Phosphoglucomutase; RPKM: Reads per kilobase of exon model per million mapped reads; RPLC: Reversed-phase liquid chromatography; SAMS: S-adenosylmethionine synthetase; SC: Serine carboxypeptidase; SUS: Sucrose synthase; TCA: Ttricarboxylic acid; TIR1: Transport inhibitor response 1 protein; TPI: Triosephosphate isomerase; TT1: TRANSPARENT TESTA 1 protein

\section{Acknowledgements}

We thank Dr. Austin Smith from World Agroforestry, East and Central Asia for critically reading this manuscript and helpful discussions. We thank the support from Service Center for Experimental Biotechnology in the Key Laboratory of Economic Plants and Biotechnology, Kunming Institute of Botany, CAS.

\section{Authors' Contributions}

$A L$ designed the research, FL and AY performed the experiments, AY, FL, and $\mathrm{AL}$ conducted the data analysis and wrote the manuscript. All the authors reviewed and approved the final version of this manuscript.

\section{Author information}

Affiliations.

Key Laboratory for Forest Resources Conservation and Utilization in the Southwest Mountains of China, Ministry of Education, Southwest Forestry University, Kunming, Yunnan Province, 650224, People's Republic of China. Anmin Yu \& Aizhong Liu.

Key Laboratory of Economic Plants and Biotechnology, Yunnan Key Laboratory for Wild Plant Resources, Kunming Institute of Botany, Chinese Academy of Sciences, Kunming, Yunnan Province, 650201, People's Republic of China.

Anmin Yu \& Fei Li.

\section{Funding}

This work was supported by National Natural Science Foundation of China (31571709, 31661143002, 31771839 and 31701123), Yunnan Applied Basic Research Projects (2016FA011).

\section{Availability of data and materials}

The data sets are included within the article and its Additional files. The sequencing data used for this study have been deposited into the NCBI Sequence Read Archive (SRA, http://www.ncbi.nlm.nih.gov/Traces/sra) database under the accession number of SRR1313230 and SRR1313233.

Ethics approval and consent to participate

Not applicable.

\section{Consent for publication}

Not applicable.

\section{Competing interests}

The authors declare that they have no competing interests.

\section{Author details}

${ }^{1}$ Key Laboratory for Forest Resources Conservation and Utilization in the Southwest Mountains of China, Ministry of Education, Southwest Forestry University, Kunming 650224, People's Republic of China. ${ }^{2}$ Key Laboratory of Economic Plants and Biotechnology, Yunnan Key Laboratory for Wild Plant Resources, Kunming Institute of Botany, Chinese Academy of Sciences, Kunming 650201, People's Republic of China.

Received: 18 September 2019 Accepted: 14 January 2020 Published online: 30 January 2020

\section{References}

1. Fan C, Xing Y, Mao H, Lu T, Han B, Xu C, Li X, Zhang Q. GS3, a major QTL for grain length and weight and minor QTL for grain width and thickness in rice, encodes a putative transmembrane protein. Theor Appl Genet. 2006; 112(6):1164-71.

2. Sakamoto T, Matsuoka M. Identifying and exploiting grain yield genes in rice. Curr Opin Plant Biol. 2008;11(2):209-14. 
3. Garcia D, Fitz Gerald JN, Berger F. Maternal control of integument cell elongation and zygotic control of endosperm growth are coordinated to determine seed size in Arabidopsis. Plant Cell. 2005;17(1):52-60.

4. Kato T, Segami S, Toriyama M, Kono I, Ando T, Yano M, Kitano H, Miura K, Iwasaki Y. Detection of QTLs for grain length from large grain rice (Oryza sativa L.). Breed Sci. 2011;61(3):269-74.

5. Liu J, Huang J, Guo H, Lan L, Wang H, Xu Y, Yang X, Li W, Tong H, Xiao Y, et al. The conserved and unique genetic architecture of kernel size and weight in maize and rice. Plant Physiol. 2017;175(2):774-85.

6. Houston NL, Hajduch M, Thelen JJ. Quantitative proteomics of seed filling in castor: comparison with soybean and rapeseed reveals differences between photosynthetic and nonphotosynthetic seed metabolism. Plant Physiol. 2009:151(2):857-68.

7. Baud S, Lepiniec L. Physiological and developmental regulation of seed oil production. Prog Lipid Res. 2010;49(3):235-49.

8. Scholza V, da Silva JN. Prospects and risks of the use of castor oil as a fuel. Biomass Bioenergy. 2008;32(2):95-100.

9. Dyer JM, Stymne S, Green AG, Carlsson AS. High-value oils from plants. Plant J. 2008:54(4):640-55.

10. Ogunniyi DS. Castor oil: a vital industrial raw material. Bioresour Technol. 2006;97(9):1086-91.

11. Atsmon D. In: Robbelen G, Downey RK, Ashri A, editors. Castor. In oilcrops of the world, their breeding and utilization. New York: McGraw-Hill; 1989. p. 438-47.

12. Qiu L, Yang C, Tian B, Yang JB, Liu A. Exploiting EST databases for the development and characterization of EST-SSR markers in castor bean (Ricinus communis L.). BMC Plant Biol. 2010;10:278.

13. You CC, Chen L, He HB, Wu LQ, Wang SH, Ding YF, Ma CX. iTRAQ-based proteome profile analysis of superior and inferior Spikelets at early grain filling stage in japonica Rice. BMC Plant Biol. 2017;17(1):100.

14. Yang MM, Dong J, Zhao WC, Gao X. Characterization of proteins involved in early stage of wheat grain development by iTRAQ. J Proteome. 2016;136:157-66.

15. Clarke VC, Loughlin PC, Gavrin A, Chen C, Brear EM, Day DA, Smith PMC. Proteomic analysis of the soybean symbiosome identifies new symbiotic proteins. Mol Cell Proteomics. 2015;14(5):1301-22.

16. Urban MO, Vasek J, Klima M, Krtkova J, Kosova K, Prasil IT, Vitamvas P. Proteomic and physiological approach reveals drought-induced changes in rapeseeds: water-saver and water-spender strategy. J Proteome. 2017;152: 188-205.

17. Le Signor C, Aime D, Bordat A, Belghazi M, Labas V, Gouzy J, Young ND, Prosperi JM, Leprince $\mathrm{O}$, Thompson RD, et al. Genome-wide association studies with proteomics data reveal genes important for synthesis, transport and packaging of globulins in legume seeds. New Phytol. 2017;214(4):1597-613.

18. Nogueira FCS, Palmisano G, Soares EL, Shah M, Soares AA, Roepstorff P, Campos FAP, Domont GB. Proteomic profile of the nucellus of castor bean (Ricinus communis L.) seeds during development. J Proteome. 2012;75(6): 1933-9.

19. Yu AM, Wang ZQ, Zhang Y, Li F, Liu AZ. Global gene expression of seed coat tissues reveals a potential mechanism of regulating seed size formation in castor bean. Int J Mol Sci. 2019;20(6):1282.

20. Greenwood JS, Bewley JD. Seed development in Ricinus communis (castor bean) .1. Descriptive morphology. Can J Bot. 1982;60(9):1751-60.

21. Wilson JE, Pestova TV, Hellen CUT, Sarnow P. Initiation of protein synthesis from the a site of the ribosome. Cell. 2000;102(4):511-20.

22. Nogueira FCS, Palmisano G, Schwammle V, Campos FAP, Larsen MR Domont GB, Roepstorff P. Performance of isobaric and isotopic labeling in quantitative plant proteomics. J Proteome Res. 2012;11(5):3046-52.

23. Feng $\mathrm{HZ}$, Chen QG, Feng J, Zhang J, Yang XH, Zuo JR. Functional characterization of the Arabidopsis eukaryotic translation initiation factor $5 \mathrm{~A}-2$ that plays a crucial role in plant growth and development by regulating cell division, cell growth, and cell death. Plant Physiol. 2007; 144(3):1531-45.

24. Thompson JE, Hopkins MT, Taylor C, Wang TW. Regulation of senescence by eukaryotic translation initiation factor 5A: implications for plant growth and development. Trends Plant Sci. 2004;9(4):174-9.

25. He MW, Wang Y, Wu JQ, Shu S, Sun J, Guo SR. Isolation and characterization of S-Adenosylmethionine synthase gene from cucumber and responsive to abiotic stress. Plant Physiol Biochem. 2019;141:431-45.

26. Shen B, Li CJ, Tarczynski MC. High free-methionine and decreased lignin content result from a mutation in the Arabidopsis S-adenosyl-L-methionine synthetase 3 gene. Plant J. 2002;29(3):371-80.
27. Roxrud I, Lid SE, Fletcher JC, Schmidt ED, Opsahl-Sorteberg HG. GASA4, one of the 14-member Arabidopsis GASA family of small polypeptides, regulates flowering and seed development. Plant Cell Physiol. 2007;48(3):471-83.

28. Schindelman G, Morikami A, Jung J, Baskin TI, Carpita NC, Derbyshire P, McCann MC, Benfey PN. COBRA encodes a putative GPI-anchored protein, which is polarly localized and necessary for oriented cell expansion in Arabidopsis. Genes Dev. 2001;15(9):1115-27.

29. Berens ML, Berry HM, Mine A, Argueso CT, Tsuda K. Evolution of hormone signaling networks in plant defense. Annu Rev Phytopathol. 2017;55:401-25.

30. Rosado A, Li RX, van de Ven W, Hsu E, Raikhel NV. Arabidopsis ribosomal proteins control developmental programs through translational regulation of auxin response factors. P Natl Acad Sci USA. 2012;109(48):19537-44.

31. Maltman DJ, Gadd SM, Simon WJ, Slabas AR. Differential proteomic analysis of the endoplasmic reticulum from developing and germinating seeds of castor (Ricinus communis) identifies seed protein precursors as significant components of the endoplasmic reticulum. Proteomics. 2007;7(9):1513-28.

32. Wu WW, Wang GH, Baek SJ, Shen RF. Comparative study of three proteomic quantitative methods, DIGE, CICAT, and iTRAQ, using 2D gel- or LC-MALDI TOF/TOF. J Proteome Res. 2006;5(3):651-8.

33. Liang C, Cheng SF, Zhang YJ, Sun YZ, Fernie AR, Kang K, Panagiotou G, LO C. Lim BL. Transcriptomic, proteomic and metabolic changes in Arabidopsis thaliana leaves after the onset of illumination. BMC Plant Biol. 2016;16:43.

34. Wang JH, Liu JJ, Chen KL, Li HW, He J, Guan B, He L. Comparative transcriptome and proteome profiling of two Citrus sinensis cultivars during fruit development and ripening. BMC Genomics. 2017;18(1):984.

35. Peng XY, Qin ZL, Zhang GP, Guo YM, Huang JL. Integration of the proteome and transcriptome reveals multiple levels of gene regulation in the rice dl2 mutant. Front Plant Sci. 2015;6:351.

36. Yang JC, Zhang JH, Huang ZL, Wang ZQ, Zhu QS, Liu LJ. Correlation of cytokinin levels in the endosperms and roots with cell number and cell division activity during endosperm development in rice. Ann Bot. 2002; 90(3):369-77.

37. Jones RJ, Roessler J, Ouattar S. Thermal environment during endosperm cell-division in maize - effects on number of endosperm cells and starch granules. Crop Sci. 1985;25(5):830-4.

38. Lee J, Han CT, Hur Y. Molecular characterization of the Brassica rapa auxin-repressed, superfamily genes, BrARP1 and BrDRM1. Mol Biol Rep. 2013;40(1):197-209.

39. Li YB, Fan CC, Xing YZ, Jiang YH, Luo LJ, Sun L, Shao D, Xu CJ, Li XH, Xiao $J \mathrm{H}$, et al. Natural variation in GS5 plays an important role in regulating grain size and yield in rice. Nat Genet. 2011;43(12):1266-70.

40. Fernie AR, Carrari F, Sweetlove LJ. Respiratory metabolism: glycolysis, the TCA cycle and mitochondrial electron transport. Curr Opin Plant Biol. 2004; 7(3):254-61.

41. Nunes-Nesi A, Araujo WL, Obata T, Fernie AR. Regulation of the mitochondrial tricarboxylic acid cycle. Curr Opin Plant Biol. 2013;16(3):335-43.

42. Guo L, Ma FF, Wei F, Fanella B, Allen DK, Wang XM. Cytosolic phosphorylating glyceraldehyde-3-phosphate dehydrogenases affect arabidopsis cellular metabolism and promote seed oil accumulation. Plant Cell. 2014;26(7):3023-35.

43. Piattoni CV, Ferrero DML, Dellaferrera I, Vegetti A, Iglesias AA. Cytosolic glyceraldehyde-3-phosphate dehydrogenase is phosphorylated during seed development. Front Plant Sci. 2017:8:522.

44. Tzafrir I, Pena-Muralla R, Dickerman A, Berg M, Rogers R, Hutchens S, Sweeney TC, McElver J, Aux G, Patton D, et al. Identification of genes required for embryo development in Arabidopsis. Plant Physiol. 2004;135(3):1206-20.

45. Zsogon A, Szakonyi D, Shi XL, Byrne ME. Ribosomal protein RPL27a promotes female gametophyte development in a dose-dependent manner. Plant Physiol. 2014;165(3):1133-43.

46. Szakonyi D, Byrne ME. Ribosomal protein L27a is required for growth and patterning in Arabidopsis thaliana. Plant J. 2011;65(2):269-81.

47. Zhang HY, Luo M, Day RC, Talbot MJ, Ivanova A, Ashton AR, Chaudhury AM, Macknight RC, Hrmova M, Koltunow AM. Developmentally regulated HEART STOPPER, a mitochondrially targeted L18 ribosomal protein gene, is required for cell division, differentiation, and seed development in Arabidopsis. J Exp Bot. 2015;66(19):5867-80.

48. Brukhin V, Gheyselinck J, Gagliardini V, Genschik P, Grossniklaus U. The RPN1 subunit of the 265 proteasome in Arabidopsis is essential for embryogenesis. Plant Cell. 2005;17(10):2723-37.

49. Zhao CS, Johnson BJ, Kositsup B, Beers EP. Exploiting secondary growth in Arabidopsis. Construction of xylem and bark cDNA libraries and cloning of three xylem endopeptidases. Plant Physiol. 2000;123(3):1185-96. 
50. Kour A, Boone AM, Vodkin LO. RNA-seq profiling of a defective seed coat mutation in glycine max reveals differential expression of proline-rich and other cell wall protein transcripts. PLoS One. 2014;9(5):e96342.

51. Tian SJ, Wu JJ, Liu Y, Huang XR, Li F, Wang ZD, Sun MX. Ribosomal protein NtRPL17 interacts with kinesin-12 family protein NtKRP and functions in the regulation of embryo/seed size and radicle growth. J Exp Bot. 2017;68(20): 5553-64.

52. Sagasser M, Lu GH, Hahlbrock K, Weisshaar B. A.thaliana TRANSPARENT TESTA 1 is involved in seed coat development and defines the WIP subfamily of plant zinc finger proteins. Genes Dev. 2002;16(1):138-49.

53. Lian JP, Lu XC, Yin NW, Ma L, Lu J, Liu X, Li J, Lu J, Lei B, Wang R, et al. Silencing of BnTT1 family genes affects seed flavonoid biosynthesis and alters seed fatty acid composition in Brassica napus. Plant Sci. 2017;254:32-47.

54. Weber $H$, Buchner P, Borisjuk L, Wobus U. Sucrose metabolism during cotyledon development of Vicia faba $L$ is controlled by the concerted action of both sucrose-phosphate synthase and sucrose synthase: expression patterns, metabolic regulation and implications for seed development. Plant J. 1996;9(6):841-50.

55. Li J, Baroja-Fernandez E, Bahaji A, Munoz FJ, Ovecka M, Montero M, Sesma MT, Alonso-Casajus N, Almagro G, Sanchez-Lopez AM, et al. Enhancing sucrose synthase activity results in increased levels of starch and adpglucose in maize (zea mays L.) seed endosperms. Plant Cell Physiol. 2013; 54(2):282-94.

56. Turner NC, Furbank RT, Berger JD, Gremigni P, Abbo S, Leport L. Seed size is associated with sucrose synthase activity in developing cotyledons of chickpea. Crop Sci. 2009:49(2):621-7.

57. Schruff MC, Spielman M, Tiwari S, Adams S, Fenby N, Scott RJ. The AUXIN RESPONSE FACTOR 2 gene of Arabidopsis links auxin signalling, cell division, and the size of seeds and other organs. Development. 2006;133(2):251-61.

58. Riefler M, Novak O, Strnad M, Schmulling T. Arabidopsis cytokinin receptor mutants reveal functions in shoot growth, leaf senescence, seed size, germination, root development, and cytokinin metabolism. Plant Cell. 2006; 18(1):40-54.

59. Hutchison CE, Li J, Argueso C, Gonzalez M, Lee E, Lewis MW, Maxwell BB, Perdue TD, Schaller GE, Alonso JM, et al. The Arabidopsis histidine phosphotransfer proteins are redundant positive regulators of cytokinin signaling. Plant Cell. 2006;18(11):3073-87.

60. Song JC, Jiang $L J$, Jameson PE. Co-ordinate regulation of cytokinin gene family members during flag leaf and reproductive development in wheat. BMC Plant Biol. 2012;12:78

61. Jiang WB, Huang HY, Hu YW, Zhu SW, Wang ZY, Lin WH. Brassinosteroid regulates seed size and shape in Arabidopsis. Plant Physiol. 2013;162(4):1965-77.

62. Qi YC, Wang FF, Zhang H, Liu WQ. Overexpression of suadea salsa Sadenosylmethionine synthetase gene promotes salt tolerance in transgenic tobacco. Acta Physiol Plant. 2010;32(2):263-9.

63. Friso G, van Wijk KJ. Posttranslational protein modifications in plant metabolism. Plant Physiol. 2015;169(3):1469-87.

64. Walling L, Drews GN, Goldberg RB. Transcriptional and post-transcriptional regulation of soybean seed protein mRNA levels. Proc Natl Acad Sci U S A. 1986:83(7):2123-7.

65. Carroll AJ, Heazlewood JL, Ito J, Millar AH. Analysis of the Arabidopsis cytosolic ribosome proteome provides detailed insights into its components and their post-translational modification. Mol Cell Proteomics. 2008; 7(2):347-69.

66. Beljkas B, Matic J, Milovanovic I, Jovanov P, Misan A, Saric L. Rapid method for determination of protein content in cereals and oilseeds: validation, measurement uncertainty and comparison with the Kjeldahl method. Accred Qual Assur. 2010;15(10):555-61.

67. Li R, Yu C, Li Y, Lam TW, Yiu SM, Kristiansen K, Wang J. SOAP2: an improved ultrafast tool for short read alignment. Bioinformatics. 2009;25(15):1966-7.

\section{Publisher's Note}

Springer Nature remains neutral with regard to jurisdictional claims in published maps and institutional affiliations.

\section{Ready to submit your research? Choose BMC and benefit from:}

- fast, convenient online submission

- thorough peer review by experienced researchers in your field

- rapid publication on acceptance

- support for research data, including large and complex data types

- gold Open Access which fosters wider collaboration and increased citations

- maximum visibility for your research: over $100 \mathrm{M}$ website views per year

At BMC, research is always in progress.

Learn more biomedcentral.com/submissions 